Published in final edited form as:

Gim, S., Zhu, Y., Seeberger, P. H., \& Delbianco, M. (2019). Carbohydrate-based nanomaterials for biomedical applications. Wiley interdisciplinary reviews: nanomedicine and nanonbiotechnology, 11(5): e1558. doi:10.1002/wnan.1558.

\title{
Carbohydrate-based nanomaterials for biomedical applications
}

Soeun Gim, Yuntao Zhu, Peter H. Seeberger, Martina Delbianco

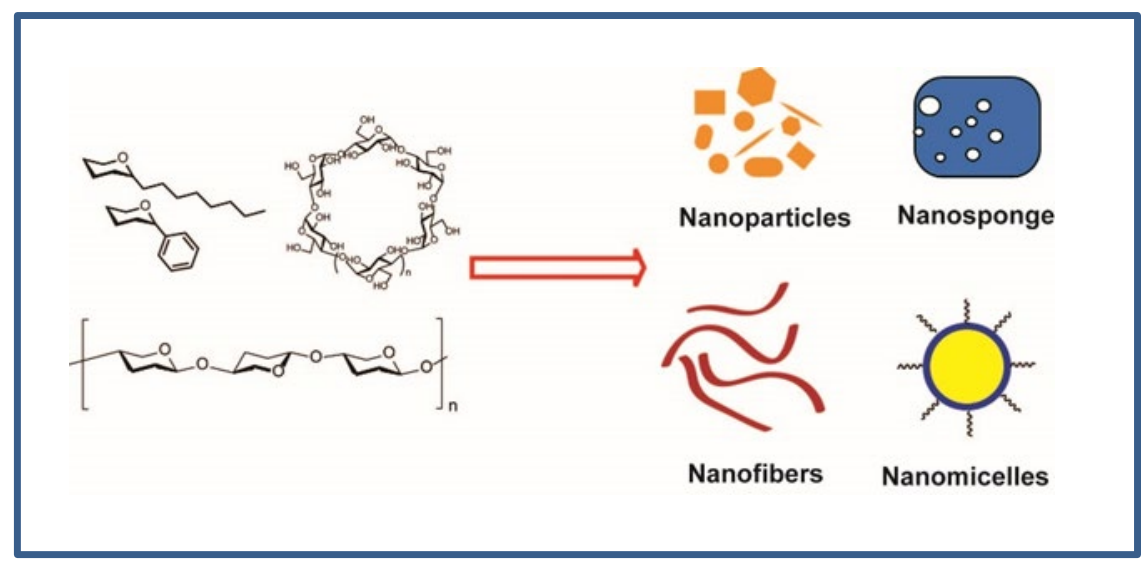

Carbohydrates aggregate to form materials with different shapes and tunable properties. These compounds are valuable for biomedical applications, including drug delivery and tissue engineering.

This article may be used for non-commercial purposes in accordance with Wiley Terms and Conditions for Self-Archiving. 


\title{
Carbohydrate-based nanomaterials for biomedical applications
}

\author{
Soeun Gim, Yuntao Zhu, Peter H. Seeberger, Martina Delbianco
}

\begin{abstract}
Carbohydrates are abundant biomolecules, with a strong tendency to form supramolecular networks. A host of carbohydrate-based nanomaterials have been exploited for biomedical applications. These structures are based on simple mono- or disaccharides, as well as on complex, polymeric systems. Chemical modifications serve to tune the shapes and properties of these materials. In particular, carbohydrate-based nanoparticles and nanogels were used for drug delivery, imaging, and tissue engineering applications. Due to the reversible nature of the assembly, often based on a combination of hydrogen bonding and hydrophobic interactions, carbohydrate-based materials are valuable substrates for the creations of responsive systems. Herein, we review the current research on carbohydrate-based nanomaterials, with a particular focus on carbohydrate assembly. We will discuss how these systems are formed and how their properties are tuned. Particular emphasis will be placed on the use of carbohydrates for biomedical applications.
\end{abstract}

Introduction

Carbohydrates comprise more than $80 \%$ of biomass, making them the most abundant class of biopolymers on earth. They mainly serve energy storage and structural functions. Recently, the regulatory role of carbohydrates in several biological processes has become evident (A. Varki; R. Cummings; J. Esko; H. Freeze; P. Stanley; G. Hart; P.H. Seeberger, 2017). Cell differentiation, proliferation and adhesion, inflammation and immune responses are connected to carbohydratecarbohydrate (CCls) (Rojo, Morales, \& Penadés, 2002) and carbohydrate-protein (CPIs) (Y. C. Lee \& Lee, $1995)$ interactions. These interactions are weak, often in the micro to millimolar range, so nature makes use of multiple weak interactions to circumvent this issue (multivalency). The concept of multivalency has been exploited by synthetic chemists in order to mimic nature (Fasting et al., 2012). Several nanostructures, coated with multiple copies of the same carbohydrate ligand, permitted to increase the CPI and CCI strength (Delbianco, Bharate, Varela-Aramburu, \& Seeberger, 2016; Jiménez Blanco, Ortiz Mellet, \& García Fernández, 2013). Enhanced water solubility and stability are also observed. Glycosylated scaffolds, such as polymers, nanoparticles, and surfaces, are potential drug delivery systems, vaccines, and therapeutics that have been reviewed extensively (Chabre \& Roy, 2013; Delbianco et al., 2016; Kiessling \& Grim, 2013; Marradi, Chiodo, García, \& Penadés, 2013; Sansone \& Casnati, 2013). The tendency of carbohydrates to form supramolecular networks, via a multitude of hydrogen bonds, guided the development of self-assembling systems (Delbianco et al., 2016).

$\mathrm{CCls}$ and CPIs are generally regulated by long complex polysaccharides. Nevertheless, for simplicity, most glycosylated-materials are based on a synthetic scaffold functionalized with multiple copies of simple mono- or oligosaccharides. Such molecules can be prepared by chemical synthesis and/or 
enzymatic methods, obtaining well-defined structures (Kadokawa, 2011; Panza, Pistorio, Stine, \& Demchenko, 2018; Pardo-Vargas, Delbianco, \& Seeberger, 2018); unnatural structures are also accessible through chemical modifications. As an alternative to synthetic compounds, polysaccharides extracted from natural sources offer a valuable substrate for the formation of materials (GarciaVaquero, Rajauria, O'Doherty, \& Sweeney, 2017; Ruthes, Smiderle, \& lacomini, 2015). Their abundance, biocompatibility, and tendency to form stable supramolecular networks are extremely appealing features for the creation of nanomaterials, like nanoparticles or gels (Figure 1). Additionally, these polymers could be easily functionalized to improve solubility, stability, encapsulation and responsiveness (Cumpstey, 2013; Fox, Li, Xu, \& Edgar, 2011; Jedvert \& Heinze, 2017). Both natural and chemically modified structures found several applications in imaging (Swierczewska, Han, Kim, Park, \& Lee, 2016; Wondraczek, Kotiaho, Fardim, \& Heinze, 2011), drug delivery (Gopinath, Saravanan, AlMaleki, Ramesh, \& Vadivelu, 2018; Z. Liu, Jiao, Wang, Zhou, \& Zhang, 2008), and tissue engineering (J. $\mathrm{Hu}$, Seeberger, \& Yin, 2016). Nevertheless, extracted polysaccharides exist as polydisperse samples with multiple lengths and branching, making the analysis, reproducibility and quality control of such materials very difficult. Due to the single chain flexibility, a detailed 3D investigation, as well as a defined structure-function correlation, is still lacking. In addition, chemical modifications, that serve to tune the polysaccharides properties, suffer from low regioselectivity, increasing the sample polydispersity even further.

Despite the challenges, carbohydrates remain an exciting substrate for biomaterial applications, due to their biological relevance and tendency to form supramolecular networks. Here, we review the recent progress in the field of carbohydrate-based nanomaterials. We will focus on supramolecular carbohydrate-based assemblies, in which the supramolecular aggregation is guided and controlled by the carbohydrate part (glycomaterials). Pre-assembled materials, further functionalized via glycosylation (glycosylated materials), will not be discussed in this review. We will start from simple architectures based on carbohydrate monomers, continuing to more complex polysaccharides-based materials. Particular focus will be given to the assemblies used for biomedical applications.

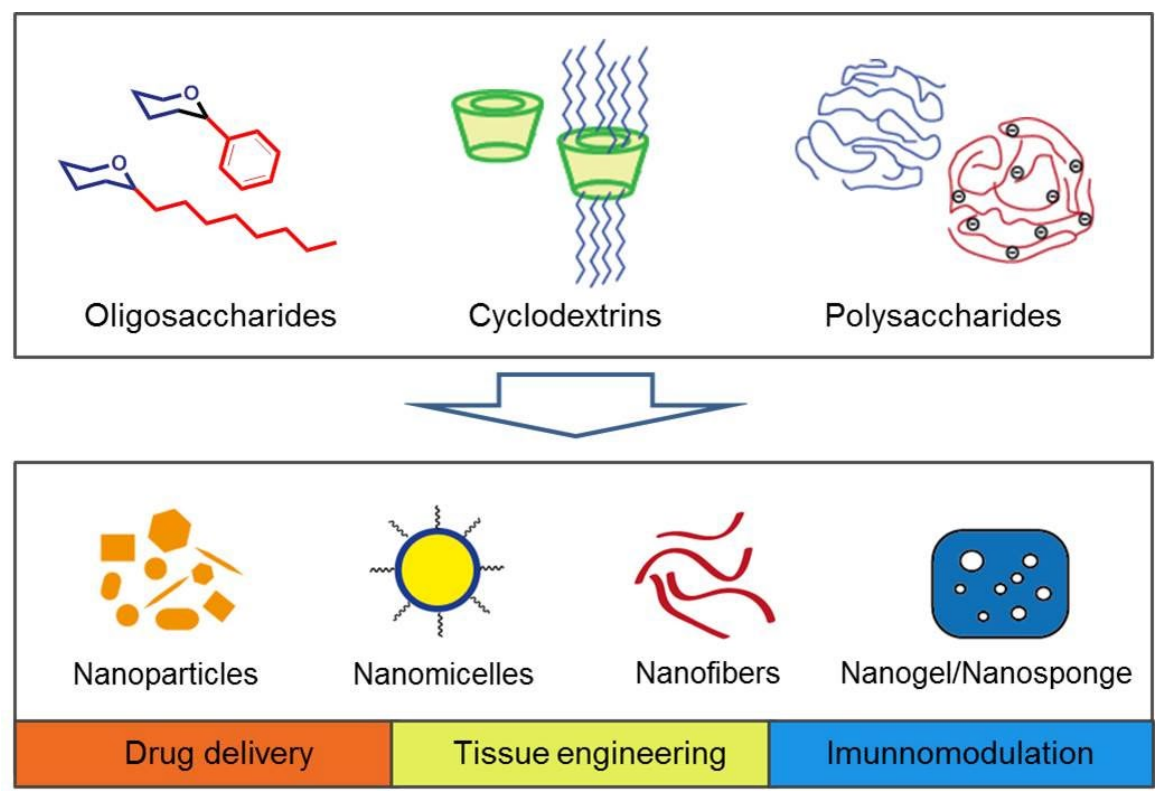

Figure 1: Schematic representation of the different classes of carbohydrates used to form nanomaterials for biomedical applications. 


\section{OLIGOSACCHARIDES}

\section{Monomers and Dimers}

Mono- and oligosaccharides have been modified extensively to give glycoamphiphiles and generate diverse morphologies like micelles, vesicles, and fibers (Figure 2). Non-covalent interactions such as hydrogen bonds, hydrophobic, and metal-ligand interactions promote the formation of the assembly. Moreover, several examples of dissociation of the assembly in response to external stimuli, such as heat, light, and ultrasound, have been reported. This behavior is particularly important for drug delivery systems, where the responsive release can be exploited to minimize drug side effects. As an example, lactose-conjugated dendrimers with a photo-responsive hydrophobic part can selectively release doxorubicin in cancel cells, upon NIR or UV irradiation (L. Sun, Ma, Dong, Zhu, \& Zhu, 2012). In addition, the amphiphilic nature of most sugar materials permits the encapsulation of both hydrophilic and hydrophobic molecules. Water-soluble compounds like enzymes, plasmid DNA, and genes as well as water-insoluble dyes can be delivered upon encapsulation into sugar micelles and vesicles (1-3) (Gour, Purohit, Verma, Puri, \& Ganesh, 2009; Ryu, Lee, Lim, \& Lee, 2007; Salim et al., 2015) .

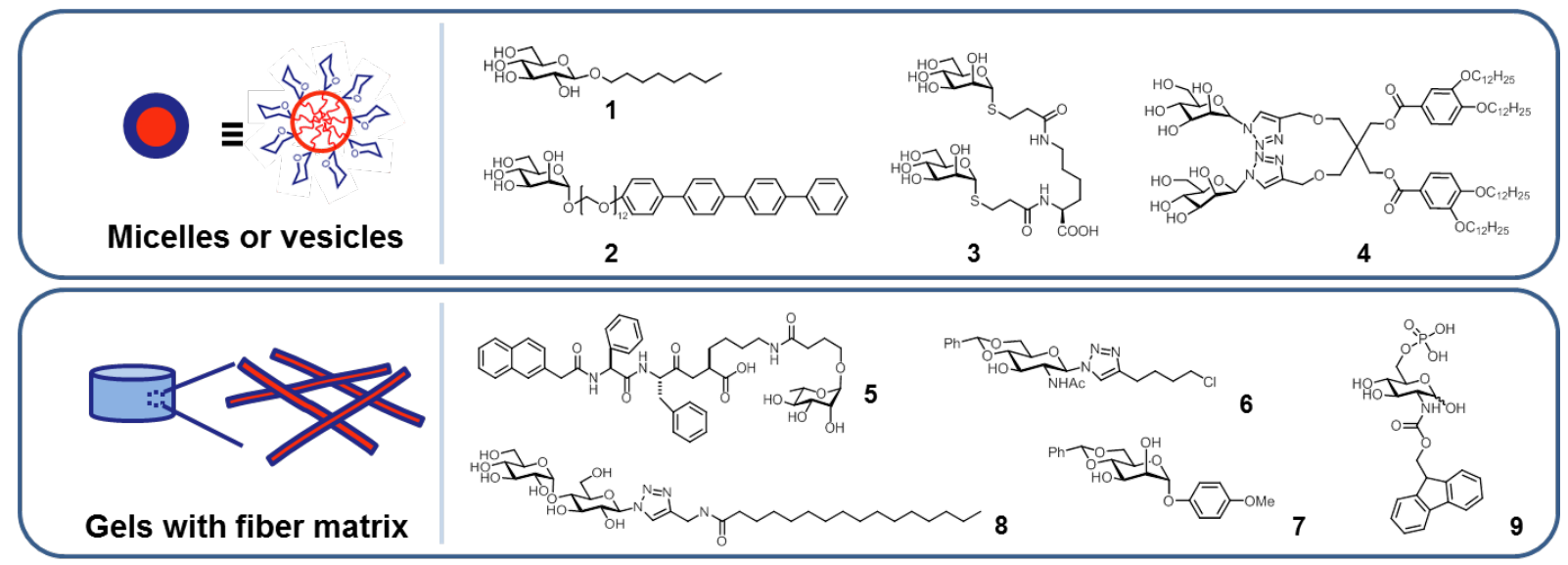

Figure 2: Chemical structures and supramolecular assembly of monosaccharides amphiphiles.

An important role of mono- and oligosaccharides is cell recognition (Lis \& Sharon, 1998). This process is based on the interaction between carbohydrate binding proteins (i.e. lectins) and carbohydrates on the cell surface and is often involved in the primary stage of pathogen infection. Sugar-assemblies have been exploited to target lectins and inhibit bacterial infections (2-4) (B. S. Kim, Yang, Ryu, Yoo, \& Lee, 2005; D. W. Lee, Kim, Park, Huang, \& Lee, 2012; Lim et al., 2007; Percec et al., 2013; Ryu et al., 2007; S. Zhang et al., 2015; S. Zhang et al., 2014). Structure and concentration of the sugar amphiphile regulates the morphology of the supramolecular complexes. At the same time, the density of the exposed sugars influence the cell recognition ability (Y. Liu, Zhang, et al., 2016). Glycoclusters based on metal-ligand interactions offer an interesting alternative. Pipyridyl-glycoclusters functionalized with the Tn-antigen ( $\alpha$-GalNAc-OR) were used for the formation of copper(II) complexes with enhanced binding to Vicia villo lectin (R. Roy \& Kim, 2003). Similarly, a catechol-functionalized iron(III) glycodendrimer better targeted E. coli ORN78 and was used as an iron delivery carrier (Yadav \& Kikkeri, 2012). Saccharide-coated $M_{12} L_{24}$ complexes based on $\operatorname{Pd}(I I)$ (Y. Liu, Zhang, et al., 2016) showed potential in Alzheimer diagnosis (Sato et al., 2015; Yan et al., 2017). The use of sugar nanostructures for immunomodulation was first reported in 2014 as the assembled nanofibrils encapsulate antigens and interact with human antibodies. In contrast to monomeric L-rhamnose, which increased antibody response, the nanofibrils base on $\mathbf{5}$ reduced the antibody response to the antigen phycoerythrin, 
suggesting that this system may be a synthetic immunomodulatory material (Zhao et al., 2014). Recently, glycopeptide nanostructures have been proposed for regenerative therapy (S. S. Lee, Fyrner, et al., 2017). Nanofibers composed of a glycopeptide bearing a trisulfated monosaccharide can mimic heparan sulfate, a polysaccharide that binds growth factors that are in turn responsible for cell proliferation and differentiation related with bone formation.

Modified mono- and disaccharides have been extensively used as low molecular weight gelators (LMWGs). Most sugar gelators are conjugated to hydrophobic moieties $(\mathbf{6 , 7 , 8 )}$, such as aliphatic chains or aromatic groups (A. Chen, Okafor, Garcia, \& Wang, 2018; Clemente, Romero, Serrano, Fitremann, \& Oriol, 2012; Guan et al., 2016; Krishnan, Raghu, Mukherjee, \& Sureshan, 2016; Mathiselvam, Loganathan, \& Varghese, 2013; Mitra, Sarkar, \& Mukhopadhyay, 2017; Pathak, Halder, Dhara, \& Yadav, 2017). These sugar-derived supramolecular structures can encapsulate hydrophobic drugs to increase drug solubility and serve as scaffolds for biomedical applications. Moreover, 3D gel matrixes from sugar gelators were exploited as a tissue engineering scaffold and for cell proliferation (Ustun Yaylaci et al., 2016). Highly elastic hydrogels, suitable for adhesion and proliferation of isolated stem cells, were obtained from a glucosyl-nucleoside bola-amphiphiles (Latxague et al., 2015). Responsive gels, that form or degrade upon an external stimulus, were developed as well. Gelation of a phosphate containing carbohydrate amphiphile 9 induced by alkaline phosphatase produced by osteosarcoma cells can suppress metastasis by blocking metabolite exchange between cells (Pires et al., 2015). A glucose-conjugated prodrug assembled into a thermo-responsive gel and was employed as a biocompatible drug with reduced inflammatory effect (Xiong et al., 2018).

Supramolecular structures formed from mono- and oligosaccharides proved to be important substrates for biomedical applications, such as bacterial infection inhibition and bone regeneration. The majority of these systems require several modifications with bulky proteins or lipid units. Moreover, most studies were limited to the use of mono- and disaccharides. With the development of synthetic techniques that allow for quick access to longer oligosaccharides, new glycomaterials, requiring less functionalization, can be envisioned (Hahm et al., 2017; Panza et al., 2018; Pardo-Vargas et al., 2018; Wen et al., 2018).

\section{Cyclodextrins}

Cyclodextrins (CDs) are cyclic oligosaccharides constituted of glucopyranose units linked $\alpha-(1,4)$, commonly produced during the degradation of starch. The most common CDs are $\alpha-, \beta-$, and $\gamma-C D s$, consisting of six, seven, and eight glucose units. Because of their cavity, CDs can form unique inclusion complexes with specific molecules, and further assemble into supramolecular structures (Crini, 2014). Hence, they are potential structural units to build nanomaterials as discussed in several excellent reviews (Bellia et al., 2009; Delbianco et al., 2016; Q. D. Hu, Tang, \& Chu, 2014; Martinez, Ortiz Mellet, \& Garcia Fernandez, 2013; Schmidt \& Barner-Kowollik, 2017; Wenz, 1994). Here, we describe recent work related to structural properties and biomedical applications of nanomaterials assembled from CD structures.

CDs usually assemble in three different packing patterns: cage, channel, and layer type superstructures (Figure 3) (Harata, 1998). In the cage pattern, the cavity is sealed by another CD. In the channel pattern, the CD molecules arrange regularly through hydrogen bonds to form linear structures, so the cavities stack together to form the channel. The layer type CDs are arranged in parallel, however, the cavities are shielded due to a half-molecule shift between the layers. These systems can further assemble into a variety of geometries, such as particles and fibers (CD-based materials). 
CD-based materials have been applied in the food and pharmaceutical industries since the 1980s (Crini, 2014) and show great potential for biomedical applications. Different methods to prepare CD-based materials in aqueous environment exist (González-Gaitano et al., 2002; Shigemitsu \& Kida, 2018; Szente, Szejtli, \& Kis, 1998; A. Wu, Shen, \& He, 2006a, 2006b). CDs and their inclusion complex nanofibers were prepared by electrospinning (Celebioglu \& Uyar, 2012, 2013a, 2013b; Kayaci \& Uyar, 2012; Uyar, Balan, Toppare, \& Besenbacher, 2009; Uyar \& Besenbacher, 2009; Uyar, Nur, Hacaloglu, \& Besenbacher, 2009). Guest-free channels can be prepared by a solvent switch from $\alpha$ - and $\gamma$-CD (Rusa et al., 2002; Uyar, Hunt, Gracz, \& Tonelli, 2006), whereas cubic crystals can be obtained from $Y$-CD (Kida, Marui, Miyawaki, Kato, \& Akashi, 2009; Marui, Kida, \& Akashi, 2009). CD drug delivery systems, allow for encapsulation of small drug molecules as well as large biomolecules (Challa, Ahuja, Ali, \& Khar, 2005; Davis \& Brewster, 2004; Del Valle, 2004; Rajewski \& Stella, 1996; Stella \& Rajewski, 1997). The antidepressants, dothiepin (DOT) and doxepin (DOX) formed 1:2 inclusion nanostructures with $\alpha-$ and $\beta$-CDs and assemble into sphere and agglomerated structures (Rajendiran, Sankaranarayanan, \& Saravanan, 2014). More complicated systems, involving the ternary complex "Guest $2 /(G u e s t 1 / \gamma-C D)$ " permitted to load two different drugs at the same time; the first guest is located in the CD cavity, and the second guest is incorporated into the intermolecular spaces between CD channels (N. Liu, Higashi, Ueda, \& Moribe, 2017). 


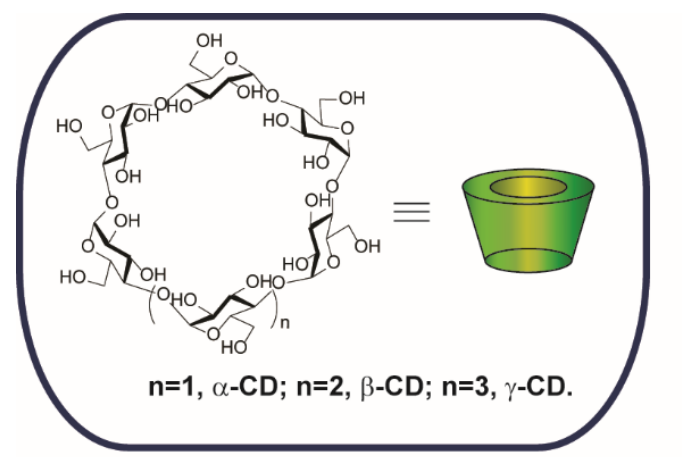

\section{Packing of unmodified CD}

\section{Chemical modifications}

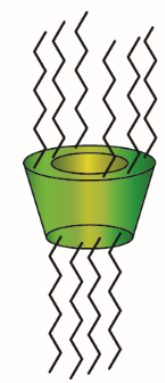

Amphiphilic $C D$

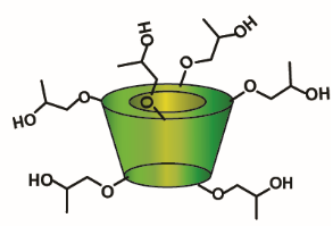

Hydroxypropyl CD

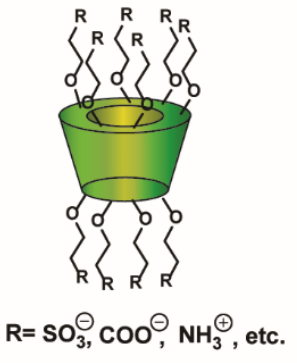

Charged CD

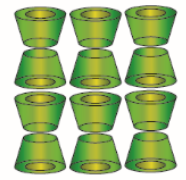

Channel type

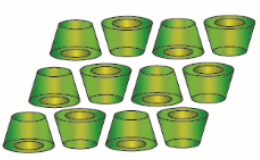

Layer type

Cage type

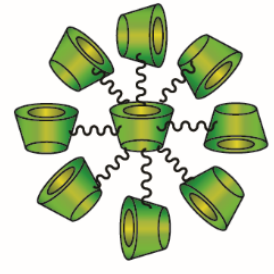

CD dendrimer

\section{Applications in drug delivery}
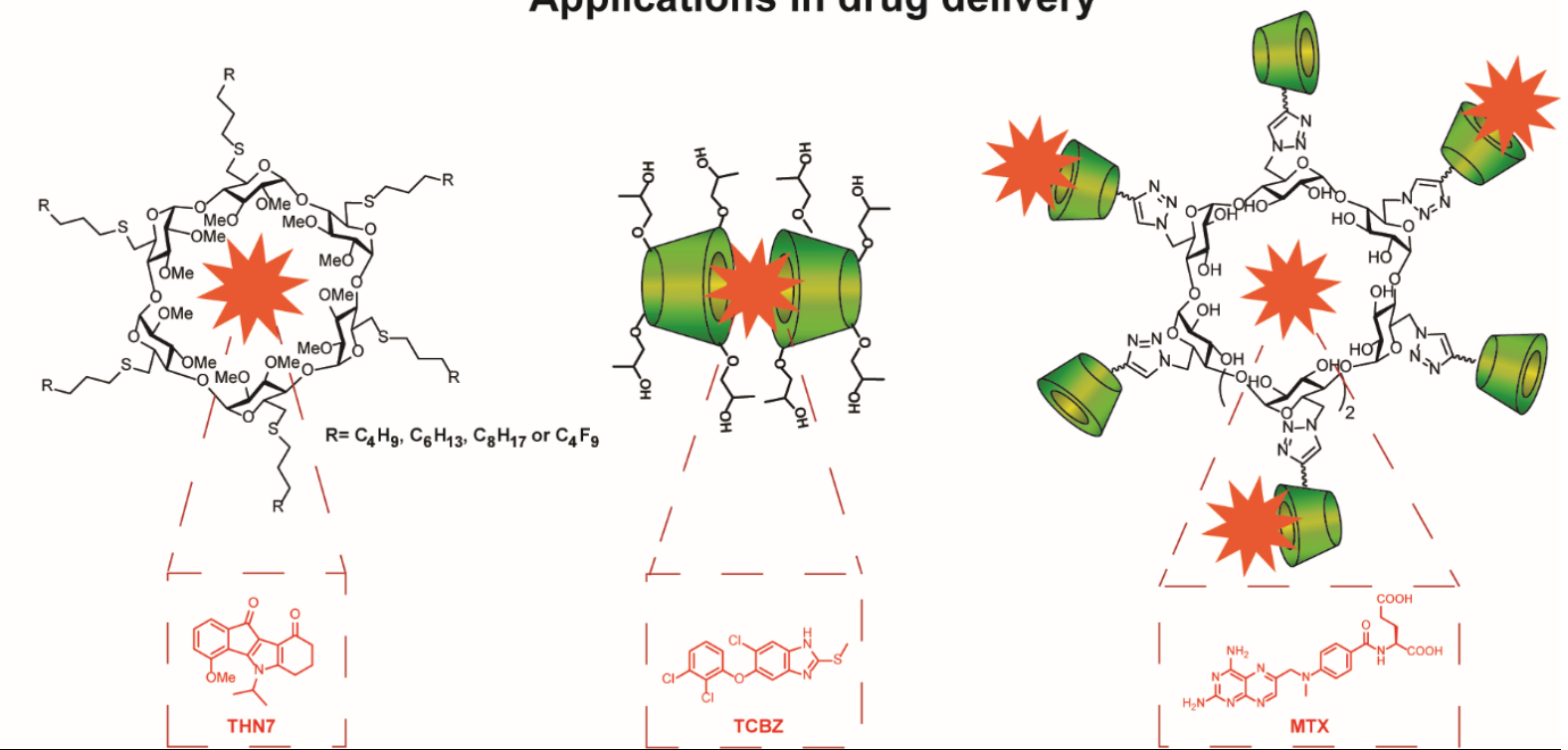

Figure 3: CD packing patterns, common CD modifications, and examples of CD systems for drug delivery applications.

Chemical modifications greatly expand pharmaceutical applications of CDs. Amphiphilic CDs engage in stronger interactions with hydrophobic drugs and can self-assemble into a variety of nanostructures, in aqueous systems. The hydrophobic part of these assemblies enters into strong interactions with biological membranes, thus increasing cellular uptake (Varan, Varan, Erdoğar, Hıncal, \& Bilensoy, 2017). $\alpha-C D$ were modified at the 6 position with diffident kinds of fluorinated and hydrocarbonated amphiphilic chains to encapsulate 4-methoxy-5-isopropyl-5, 6, 7, 8-tetrahydroindeno [1, 2-b] indole-9, 10-dione (THN7), an inhibitor of casein kinase 2, and form nanoparticles of around $100 \mathrm{~nm}$ diameter size (Figure 3)(Nacereddine et al., 2018). 
2-Hydroxypropyl cyclodextrins (HP-CDs) are widely used for drug delivery. Upon random methylation, $\beta-C D$ and HP- $\beta-C D$ served as carriers for drug nebulization (Evrard et al., 2004). An aqueous cyclosporin A eye drop was developed based on both natural CDs and HP-CDs (Jóhannsdóttir, Jansook, Stefánsson, \& Loftsson, 2015). HP- $\beta-C D /$ budesonide microparticles were spray-dried to treat lung inflammation (Dufour et al., 2015). The inclusion complex between triclabendazole (TCBZ) and HP- $\beta-C D$ or methyl$\beta$-cyclodextrin (Me- $\beta$-CD) can form different superstructures, that are highly soluble for drug delivery applications (Figure 3) (Real, Leonardi, Williams, Repka, \& Salomon, 2018). The advantage of HP-CDs was illustrated for the $C D / G$ riseofulvin (GF) complex. Although $\beta-C D$ s and Me- $\beta-C D$ s were as effective in stabilizing the drug suspensions and reducing the size of drug nanoparticles, HP- $\beta-C D$ showed the highest efficacy (Meng, Yang, Keyvan, Michniak-Kohn, \& Mitra, 2012).

Hydrophilic CD derivatives, bearing charged functional groups, were developed as an alternative to amphiphilic CDs. Non-ionic amphiphilic CD and polycationic amphiphilic CD functionalized with amino groups were used as nanocarrier for paclitaxel. The strong positive charge helped to increase the loading capacity of the nanoparticles (Varan, Benito, Mellet, \& Bilensoy, 2017). Moreover, charged CDs are interesting substrates to prepare nanosponges, permitting high loading and better delivery for a wide variety of drugs (Selvamuthukumar, Anandam, Krishnamoorthy, \& Rajappan, 2012). The negatively charged sulfo-butylether- $\beta$-cyclodextrin (SBE- $\beta-C D)$ was crosslinked by epichlorohydrine and form a nanosponge, used as deliver system for repaglinide (Olteanu, Aramă, Radu, Mihăescu, \& Monciu, 2014). Carbonate and carboxylate functionalized cyclodextrins also assembled into nanosponges for acyclovir encapsulation (Lembo et al., 2013). Moreover, a glutathione (GSH) responsive nanosponge was developed by crosslinking $\beta-C D$, pyromellitic dianhydride and 2 hydroxyethyl disulfide, with potential for doxorubicin encapsulation. The drug release profile was accelerated in the presence of increasing amounts of glutathione (GSH) (Trotta et al., 2016).

New modifications are studied to produce novel CD materials with improved performance. Nanocarriers formed by epichlorohydrine crosslinked CD polymers can significantly enhance the solubility of sorafenib in water (Giglio et al., 2018). Multi-responsive CD vesicles, consisting of $\left(N, N^{\prime}\right.$ bis(ferrocenylmethylene)-diaminohexane) and ( $\gamma$-hydroxybutyric- $\beta$-cyclodextrin, $\gamma$-HB- $\beta$-CD), showed redox-responsive behavior. The same system is $\mathrm{pH}$ responsive and reacts to the presence of metal ions such as $\mathrm{Cu}^{2+}$ (Huacheng Zhang et al., 2010). Dendrimers based on $\beta-C D$ and ethylenediamine accommodate naproxen and naltrexone in gaps of the dendritic structure as well as in the hydrophobic cavities of the CDs (Martinez et al., 2013). A similar $\beta$-CD dendrimer provided a controlled drug delivery system for methotrexate (MTX) for cancer treatment (Figure 3) (Toomari, Namazi, \& Akbar, 2015). Amphiphilic $\beta-C D$ nanoparticles were developed as nanocarriers for doxorubicin (DOX). The assemblies were further functionalized with mannose, to facilitate the cancer cell targeted drug delivery. The system showed good tumor growth inhibition in the murine xenograft tumor models (Ye et al., 2016)

Several nanomaterials were prepared from different $C D$ units and applied to the development of drug delivery systems, nevertheless, structure-function relationship have yet to be established. A better understanding of the relationships between the chemical modification, preparation, and structural property of $C D$ materials, will help the design and creation of new $C D$ nanostructures for the specific needs. 


\section{POLYSACCHARIDES}

\section{Neutral polysaccharides}

\section{Cellulose}

Cellulose is the most abundant biopolymer on earth and a major structural component in plants, algae, fungi, and bacteria (Klemm, Heublein, Fink, \& Bohn, 2005). D-glycopyranose monomers are connected to each other with $\beta$-(1,4)-glycosidic linkage forming elementary fibrils (protofibrils). Cellulose microfibrils arise from a large number of inter- and intramolecular interactions of the protofibrils, ensuring high mechanical strength, durability, and water-insolubility. These features allow for the use of cellulose in the paper, textile, filter, and building material industry (Moon, Martini, Nairn, Simonsen, \& Youngblood, 2011). Recently, nanocellulose (NC) has gained attention as material (Thomas et al., 2018). Three main classes of NC exist: cellulose nanocrystals (CNCs), nanofibrillated cellulose (NFC), and bacterial nanocellulose (BNC). NC can be extracted from various biosources and it is easily chemically or physically modified (Kargarzadeh et al., 2018). Like other nanomaterials, NC shows a high surface to volume ratio and improved solubility compared to natural cellulose. Here, we will focus on materials obtained by self-assembly of substituted cellulose, since NC has been extensively reviewed (Amalraj, Gopi, Thomas, \& Haponiuk, 2018; Jorfi \& Foster, 2015; Picheth et al., 2017; Seabra, Bernardes, Fávaro, Paula, \& Durán, 2017).

The limited water solubility of cellulose is a critical obstacle for biomedical applications. For a better usage of cellulose in drug delivery, wound healing, and tissue/regenerative engineering, structural modifications have been introduced to decrease inter- and intramolecular hydrogen bonding (D. Roy, Semsarilar, Guthrie, \& Perrier, 2009). The cellulose backbone, rich in hydroxyl groups, can be esterified and etherified. Due to the poor solubility of cellulose in common solvents, ionic liquids, such as 1-nbutyl-3-methylimidazolium chloride ( $\mathrm{BmimCl})$ and 1-n-alkyl-3-metylimidazolium chloride ( $\mathrm{AmimCl})$, are generally employed. Cellulose acetate (CA), ethylcellulose (EC), hydroxypropylcellulose (HPC), and carbohymethylcellulose (CMC) are the most common cellulose derivatives (Figure 4), with improved water solubility. Hydrophobic segments, like poly(L-lactic acid), have been grafted onto the cellulose backbone to give rise to amphiphilic copolymers (Dai \& Si, 2017; Guo, Wang, Shu, Shen, \& Sun, 2012).

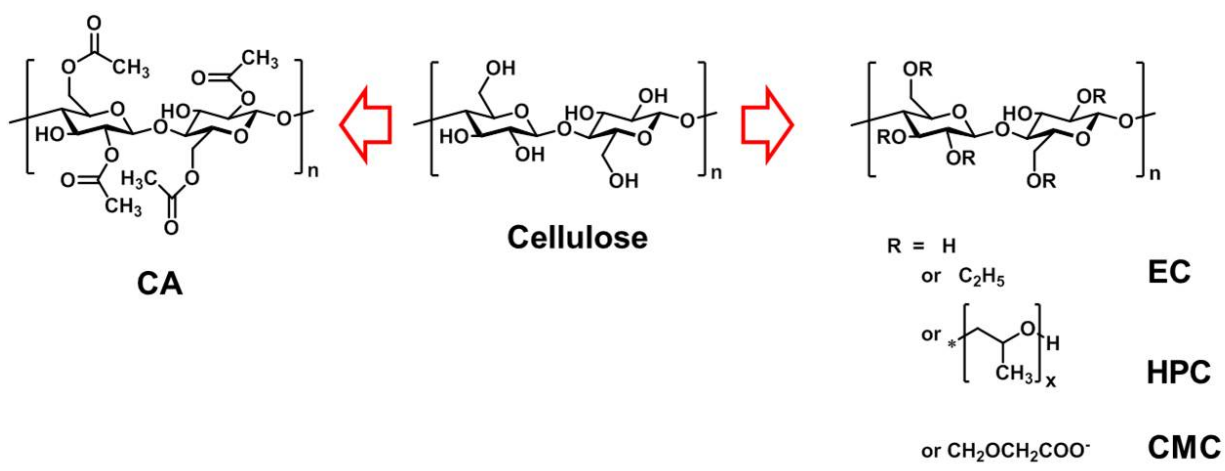

Figure 4: Chemical structure of cellulose and its most common derivatives.

CA is the acetate ester of cellulose, obtained from the reaction of cellulose with acetic anhydride and acetic acid in the presence of sulfuric acid. The solubility of CA is influenced by the degree of 
acetylation.(Fischer et al., 2008) Earlier studies on CA mainly focused on the formation of cellulose beads, resulting in a commercially available system for medical applications (Milovanovic et al., 2016). CA beads are prepared via oil-in-water emulsion/solvent evaporation, offering high mechanical strength, suitable for bone tissue engineering (Kumbar et al., 2011). Cellulose acetate phthalate (CAPh) successfully generated CAPh-dye beads by encapsulation, which were used as visually readable labels in lateral flow immunoassays (Schulze et al., 2016). Since the development of electrospinning for nanobiotechnology, improving drug encapsulation efficiency and easing fabrication (Samadian, Mobasheri, Hasanpour, \& Majid, 2017), the recent research on CA focuses on electrospun fibers (Khoshnevisan et al., 2018; Sharaf \& El-Naggar, 2018). Chlorohexidine-containing CA electrospun nanofibers showed antibacterial activity against oral pathogens, permitting a release of the drug over 90 days (De Carvalho et al., 2017). Dexamethasone-loaded electrospun CA scaffolds provided a good environment for cell growing and proliferation, suggesting the possibility to reduce implant-associated acute inflammations and impede implant failure (Tsiapla et al., 2018). Functionalized stimuliresponsive CA were also developed. A boronic acid ligand-functionalized CA nanofiber, which is able to selectively bind and release glycoproteins (e.g. ovalbumin) depending on the $\mathrm{pH}$, was used in diagnostics (Dong et al., 2018).

Short aliphatic moieties were used to functionalize the cellulose backbone to give EC, HPC, and other derivatives, that are readily soluble in common organic solvents. The hydrophobic modification allows for the self-assembly of the cellulose derivatives in aqueous solution and encapsulation of hydrophobic dyes (Xiaohui Wang, Guo, Li, Chen, \& Sun, 2012). In addition, EC can form gels by the solvent-exchange method. Antimicrobial agents were encapsulated in such gels providing a simple syringe injectable drug for periodontitis (Phaechamud \& Mahadlek, 2015). Atom transfer radical polymerization (ATRP) is the most widely used technique for further modification of cellulose derivatives (Kang, Liu, \& Huang, 2015; D. Roy et al., 2009). Generally, the cellulose hydroxyl groups are modified with 2bromoisobutyryl bromide to initiate the polymerization reaction. Light sensitive triblock copolymers were successfully obtained by ATRP of EC and spiropyran ether methacrylate (SPMA). The SPMA light responsive moieties permitted a wavelength dependent controlled drug release (B. Wang, Chen, Yang, Yang, \& Liu, 2014). An alternative system uses pendant disulfide linkages to form a HPC crosslinked structure with excellent colloidal stability and selective drug release behavior, in the presence of a reducing agent (Rahimian, Wen, \& Oh, 2015).

The introduction of negative charges onto the cellulose backbone, not only affects the supramolecular structure formation, but also the bioactivity of the resulting aggregates. CMC is the most common charged cellulose derivative, bearing negative carboxymethyl groups. The carboxylic groups make cellulose soluble in water and chemically reactive. Due to its negative nature, CMC can generate supramolecular structure with positive charged polymers or metals (Figure 5) (Agarwal et al., 2015; Barkhordari, Yadollahi, \& Namazi, 2014; Upadhyaya, Singh, Agarwal, Pandey, et al., 2014). CMC and quaternary ammonium substituted cellulose formed a ampholytic hydrogel responsive to $\mathrm{pH}$ and salt concentration, which makes a good candidate for tissue engineering (Chang, He, Zhou, \& Zhang, 2011). Similarly, a mixture of lysozyme (Ly), a globular positive charged protein, and CMC is a promising drug delivery carrier (Zhenshun Li, Wang, et al., 2017; K. Zhu et al., 2013). This system can incorporate quantum dots for cell imaging (Zhenshun Li et al., 2015). Hydroxyl groups of CMC and acidfunctionalized multi-walled carbon nanotube (MWCNT) generated a hybrid nanocomposite hydrogel via strong hydrogen bonding between the two components, leading to a sustained release of diclofenac sodium (Mandal, Das, Rameshbabu, Dhara, \& Pal, 2016). Following the same idea, a $\mathrm{CMC} /$ graphene oxide $(\mathrm{GO})$ hydrogel was obtained. This gel was converted into spherical beads by 
addition of iron ions (Rasoulzadeh \& Namazi, 2017). Even simple organic molecules, like citric acid, can crosslink CMC and form hydrogels with enhanced mechanical properties, and suitable for topical chemotherapy (Capanema et al., 2018).

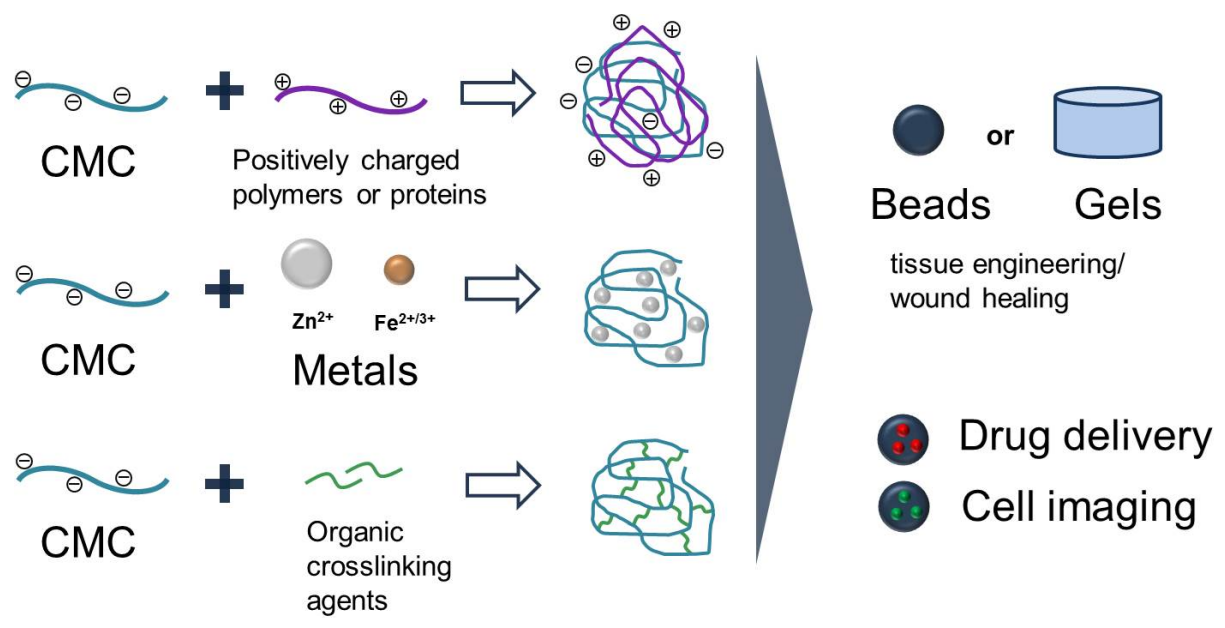

Figure 5: Co-assembly of $\mathrm{CMC}$ to form nanomaterials.

CMC has been modified in many ways to tune its properties for biomedical applications. Acetylated CMC improved drug coupling efficiency and colloidal stability (Hoang et al., 2015). Mucoadhesive properties were obtained by conjugation of L-cysteines to the CMC backbone (Laffleur \& Messirek, 2016). Tumor targeting was tackled with covalent conjugation of cancer drugs and folate ligands to CMC (Dai et al., 2015). $\beta$-CD grafted CMC gels showed more effective tetracyclin-loading efficiency as compare to normal CMC gel (Jeong et al., 2018). Insertion of the photo-active cinnamic acid hydrazide moieties into the oxidized dialdehyde CMC core generated an adjustable photo-crosslinked hydrogel with improved mechanical properties (Monier, Abdel-Latif, \& Ji, 2016). Crosslinking performed by microwaved assisted radical transfer increased the hydrogel stability and improved the sustained drug release (Sood, Gupta, Agarwal, Dev, \& Pathania, 2017).

\section{Dextran}

Dextran, a glucose homopolysaccharide based on an $\alpha-(1,6)$ backbone with $\alpha-(1,2), \alpha-(1,3)$, or $\alpha-(1,4)$ side chains, is a highly water-soluble bacterial glycan with good biocompatibility and biodegradability with the tendency to form nanomaterials, and widely used in the pharmaceutical industry (Naessens, Cerdobbel, Soetaert, \& Vandamme, 2005). Many reviews summarize the use of dextran for drug delivery and tissue engineering (Bisht \& Maitra, 2009; Debele, Mekuria, \& Tsai, 2016; Mehvar, 2000; Miao, Wang, Zeng, Liu, \& Chen, 2018; Mizrahy \& Peer, 2012; Mokhtarzadeh, Alibakhshi, Hejazi, Omidi, \& Dolatabadi, 2016; G. Sun \& Mao, 2012; Van Tomme \& Hennink, 2007). We will focus on the recent advances on assemblies and nanostructures based on dextran and its chemical derivatives.

Several dextran aggregates, of different size and shape, were produced and used for drug encapsulation. Microcapsules based on natural dextran with different molecular weight (10 kDa - 500 $\mathrm{kDa}$ ) were prepared by spray drying. The drug budesonide was co-fibred at different drug-to-dextran ratios, showing that a 1:10 drug-to-polymer ratio can successfully deliver the drug to the colon to treat acetic acid-induced colitis (Varshosaz et al., 2011). Hybrid dextran nanoparticles with core-shell structure were developed to carry zidovudine, an antiviral drug extensively used for combating the global pandemic-HIV/AIDS. The nanocomplex of zidovudine with dextran, stearic acid, and poly (ethylene glycol) was obtained through a double emulsion solvent evaporation method. Further tests 
demonstrated the increased cellular internalization of the drug loaded nanoparticles, when compared with the free drug (Joshy et al., 2018).

Chemical modifications permitted the introduction of functional groups that greatly extended the biomedical application of natural dextran (Figure 6). Acetalated dextran (Aca-DEX) 10, easily prepared from natural dextran, is one of the most commonly used derivatives (Bachelder, Pino, \& Ainslie, 2016). A microparticulate-based delivery system prepared by electrospray. The recombinant protective antigen and the adjuvant were encapsulated in acetalated dextran particles, to provide a subunit anthrax vaccine (Gallovic et al., 2016). Depending on the degree and type of acetal modification, the degradation of Aca-DEX can be controlled. Microparticles with tunable degradation rates showed advantages compared to poly(lactic-co-glycolic acid) and iron oxide, two commonly used materials for immunotherapy (Broaders, Cohen, Beaudette, Bachelder, \& Fréchet, 2009). Because of its instability at low $\mathrm{pH}$ conditions, acetalated dextran was used as acid-responsive biodegradable material. Aca-DEX particles were able to carry either hydrophobic or hydrophilic payloads and released them at mild acidic conditions (pH 5) (Bachelder, Beaudette, Broaders, Dashe, \& Fréchet, 2008). Aca-DEX-based microparticles with different hydrolysis rates were used for gene delivery in phagocytic and nonphagocytic cells (J. A. Cohen et al., 2010). Compared with commercially available polyester and poly(Llactide) (PLA), Aca-DEX nanofiber produced by electrospray gave a faster steady-state doxorubicin (DXR) release. Mice treated with DXR-loaded Aca-DEX resulted in 57\% long-term survival (120 days) compared to $20 \%$ survival, following treatment with DXR-loaded PLA (Yoo et al., 2018). To increase recognition and subsequent stimulatory effects of toll-like receptor, imiquimod was encapsulated in Aca-DEX microparticles, and rapidly released under acidic lysosomal vesicles. This system is a potent delivery platform for vaccine adjuvants (Bachelder et al., 2010). Aca-DEX nanoparticles, loaded with paclitaxel (PTX), gave sustained release of drug against traumatic spinal cord injury (W. Liu, Quan, et al., 2018). Aca-DEX/camptothecin porous microparticles were prepared via a double emulsion water/oil/water $(\mathrm{w} / \mathrm{o} / \mathrm{w})$ evaporation method. The tuned particle shape minimized macrophage clearance, favoring lung penetration to deliver the drug to the pulmonary cavity (Meenach et al., 2012). A phenyl acetalated dextran derivative was synthesized and the resulted nanoparticle used as image guided siRNA carrier for cyclooxygenase-2 (COX-2) down regulation. Potential application against autoimmune diseases, gastric inflammation and cancer were suggested (Z. Chen, Krishnamachary, Penet, \& Bhujwalla, 2018). 

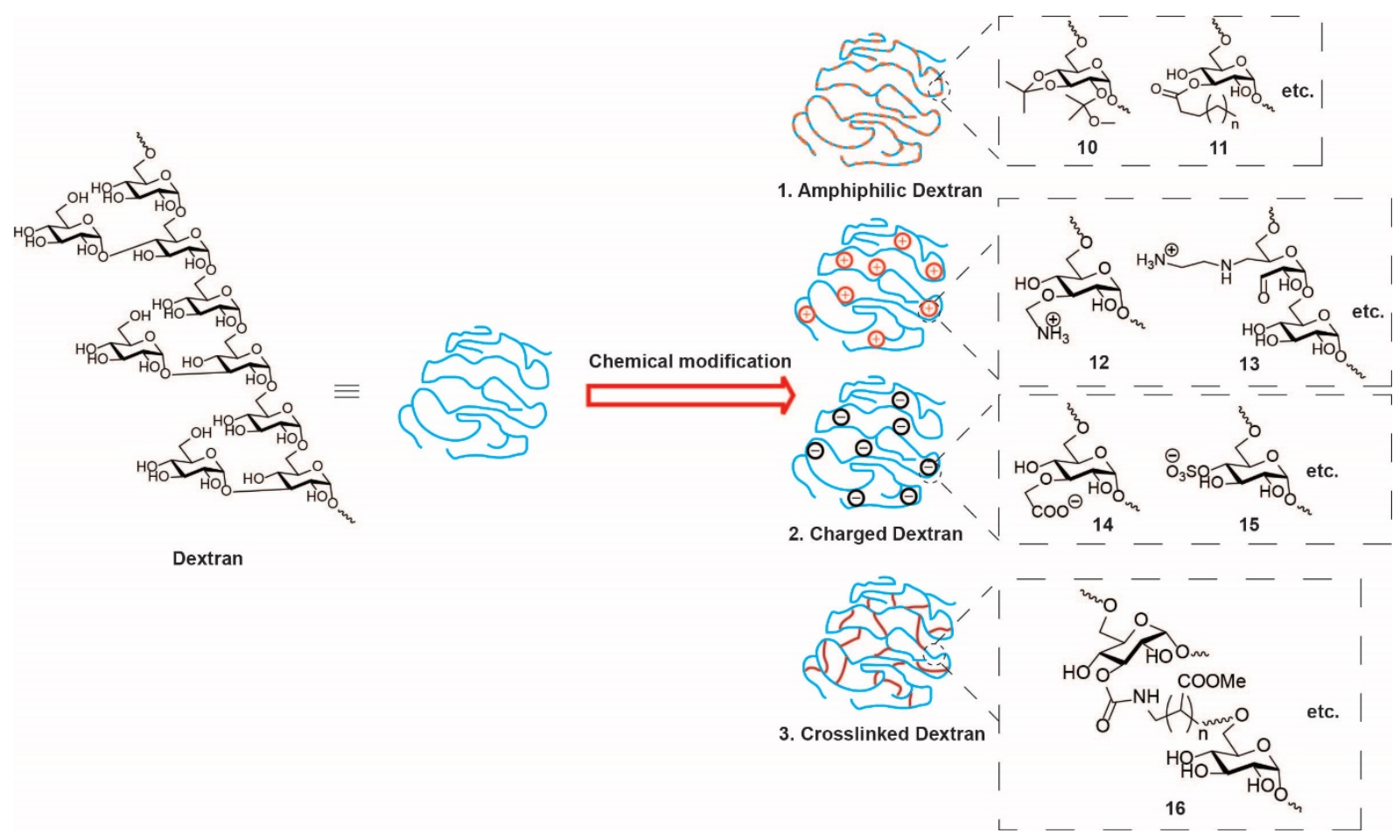

Figure 6: Cartoon depiction of the most common dextran modifications.

Amphiphilic dextran derivatives $\mathbf{1 1}$ can be prepared by grafting hydrophobic side chains on the backbone hydroxyl groups (Raemdonck, Demeester, \& De Smedt, 2009). Several examples were prepared through esterification with stearic acid (SA) and cholesterol (Chol) and used as carriers to encapsulate rapamycin, a hydrophobic cancer drug. Generally, the particle size increases with increasing particle hydrophilicity (Shaki, Ganji, Kempen, Dolatshahi-Pirouz, \& Vasheghani-Farahani, 2018). A dextran based multidrug carrier was developed by adding 3-pentadecylphenol to the dextran side chains. The nano-vesicle can carry, at the same time, the hydrophobic drug camptothecin (CPT) and the hydrophilic drug doxorubicin (DOX), thus improving their synergistic killing of breast and colon cancer cells. This system released its cargo in response to the esterase assisted cleavage in the cell (Pramod, Shah, Chaphekar, Balasubramanian, \& Jayakannan, 2014). Monodisperse nanogels were obtained through the self-assembly of amphiphilic poly (D-/L-lactide)-grafted dextran (Nagahama, Mori, Ohya, \& Ouchi, 2007). Nanogels composed of dextran and oligolactide (OLA) chains connected via disulfide bonds (Dex-g-SS-OLA) were developed as responsive systems to the reductive cytosol environment, to achieve efficient drug delivery. The addition of galactose (Gal) residues on the nanogel enhanced cellular uptake, by receptor-mediated endocytosis. Further addition of a secondary oligoamine (tetraethylenepentamine) group promote the escape from the endosomes, acting as a proton sponge (Ohya, Takahashi, \& Kuzuya, 2018). Supramolecular hydrogels were prepared though the formation of an inclusion complex between poly(ethylene glycol) grafted dextran and $\alpha$-cyclodextrins $(\alpha-C D s)$. Interestingly, the complexes showed a unique reversible gel-sol phase transition with hysteresis (Huh et al., 2001). A boronate-linked dextran/cholesterol nanoassembly was prepared for nuclear drug translocation and improved the drug efficacy, as shown with doxorubicin (J.-Y. Zhu et al., 2015). Other cancer targeted drug delivery systems were obtained with translocator protein (TSPO) ligand-dextran conjugates (TSPO-Dex) that formed tightly aggregated particles, with a spherical or rodlike shape (Lopalco et al., 2018). A dextran-platinum (IV) conjugate nanoparticle was used to deliver DOX in a reduction-responsive manner. The collapse of the assembly, due to the reduction of platinum (IV) by glutathione (GSH), triggered the release of DOX. The presence of DOX and Pt(II) was found to be very effective for antitumor therapy (He et al., 2015). 
Natural dextran can be oxidized with peroxide or periodate, forming a dialdehyde structure. This modification can be used as handle to form Schiff base linkages 13. Different amine bearing drugs, such as DOX, can be attached to the dextran nanoparticles and released at low $\mathrm{pH}$, due to the lability of the Schiff linkage (Wasiak et al., 2016). Amphiphilic dextran derivatives, synthesized from oxidized dextran and stearic acid (SA) using different diamines, self-assemble into core-shell micelles. Curcumin was selected as a model drug to show that these dextran carriers have excellent drug loading capacity and drug encapsulation efficiency (Chai et al., 2017).

Hydrophilic modification of dextran with charged functional groups, such as negative carboxylic or sulfuric acids or positive amino groups, can be easily obtained. A dextran sulfate (DS)-based drug delivery system for controlled and sustained release of DOX was developed. This DS-DOX complexes can be further encapsulated into injectable agarose hydrogels and achieve sustained local delivery of low-dose DOX against breast cancer (Niu, Zhang, \& Zhong, 2017). With dextran sulfate 15 as the backbone and $5 \beta$-cholanic acid, spherical nanoparticles were developed as carrier for methotrexate (MTX) against rheumatoid arthritis (Heo et al., 2017). Interestingly, dextran sulfate was also found to stabilize the positively charged liposome (Cámara, Lurgo, Fanani, \& Wilke, 2018). A carboxymethyl dextran $\mathbf{1 4}$ hydrogel with porous morphology showed responsiveness to $\mathrm{pH}$ and ionic strength of the medium. The diffusion rates of proteins through the hydrogel increased with $\mathrm{pH}$, since repulsion of ionized carboxyl groups enlarge the porous gel structure (Rhongsheng Zhang, Tang, Bowyer, Eisenthal, \& Hubble, 2005). A novel, pH-responsive micelle, composed of dextran and poly(oleic acid) side chain was synthesized for oral delivery of nifedipine. The system presents a spherical morphology at critical micelle concentration, and a rod-like assembly beyond that concentration (Karmakar et al., 2018). The modification of dextran with amino groups provides a polycationic biocompatible material especially suitable for gene delivery (Azzam, Eliyahu, Makovitzki, \& Domb, 2003), as exemplified by the poly(ethylene imine) (IPEI) grafted onto dextran. An acid-sensitive, biocompatible, microparticulate system based on spermine grafted acetalated-dextran was prepared for siRNA delivery, and achieved efficient gene knock down in HeLa-luc cells with minimal toxicity (J. L. Cohen et al., 2011). Additional spermine grafted acetalated dextran-functionalized nanoparticles were developed for dual-drug delivery and targeting of cardiac fibroblasts for cellular reprogramming (M. P. Ferreira et al., 2018). A combination of histidine grafted dextran (Dex-His) and dextran-stearic acid (Dex-SA) was used to construct nano-micelles, to responsively deliver DOX to cancer cells (Jafarzadeh-Holagh, HashemiNajafabadi, Shaki, \& Vasheghani-Farahani, 2018). A hydrogel based on oxidized dextran and epsilonpoly(L-lysine) showed good adhesive strength against collagen sheets, extending the scope of dextranbased materials to tissue engineering applications (Hyon, Nakajima, Sugai, \& Matsumura, 2014). Several systems assembled from two opposite-charged dextran derivatives exist. Hollow nanospheres were prepared from the negatively charged acetic acid grafted on dextran (Dex-CA) 14 and the positively charged ethylamine dextran derivative (Dex-BH) 12. At pH 5.0, the two components selfassembled into well-defined nanospheres or tubular structures (G. Sun \& Chu, 2009). An albumin release study indicates their potential as drug delivery vehicles (G. Sun \& Chu, 2011).

Other polymeric backbones crosslinked with dextran 16 also found several applications for drug delivery and tissue engineering. The common strategy is to graft a monomer, such as methacrylate, on the dextran backbone, and perform the polymerization to obtain the crosslinked hydrogel or nanostructures (L. Ferreira, Gil, \& Dordick, 2002; Lévesque, Lim, \& Shoichet, 2005; G. Sun et al., 2011; T. Wang, Nie, \& Yang, 2012; Wei et al., 2017). These strategies can enable further expand the structure and applications of dextran nanomaterials, since the crosslinked material properties are largely affected by the polymer backbones. 
Other neutral polysaccharides based on different sugar monomers and glycosidic linkages have been studied. Starch, a storage copolymer based on multiple glucose units, is composed of amylose and amylopectin. Amylose is a poly $\alpha$-(1-4)-glucoside with a helical three-dimensional structure that can encapsulate hydrophobic molecules in the inner cavity of the helix that in turn stabilizes the helix. Therefore, amylose has been employed for the controlled drug release (Gao et al., 2017; L. Zhang et al., 2016). Amylopectin, glycogen, and pullulan, are branched polyglucosides based on both $\alpha-(1-4)$ and $\alpha$-(1-6) linkages. They originated from plant, animal and microbial sources, respectively, and have been widely modified for pharmaceutical purposes (Gopinath et al., 2018). Among them, the use of pullulan for drug delivery and tissue engineering has been broadly studied (Singh, Kaur, \& Kennedy, 2015; Singh, Kaur, Rana, \& Kennedy, 2016). Several modification strategies such as oxidation, esterification, etherification, carboxymethylation, hydroxypropylation, and hydroxyethylation have been used to tune polysaccharide properties (H. Hu, Li, et al., 2016; D. Li, Feng, Chen, Ding, \& Chen, 2018; Masina et al., 2017; Tan et al., 2018). The natural polysaccharide dendrimer, glycogen, was studied as a mucoadhesive drug delivery carrier (Perrone, Lopalco, et al., 2017; Perrone, Lopedota, et al., 2017).

Besides glucose, sugar monomers like mannose, galactose, and arabinose are part of other classes of polysaccharides. Of particular relevance, hemicelluloses, composed of xylan and arabinoxylan, inulin, guar gum and locust bean gum have been exploited as a theradiagnostic tool (Braz et al., 2018; George, Shah, \& Shrivastav, 2018; W.-Q. Kong et al., 2017; W. Kong et al., 2018; Mandracchia et al., 2017; Petzold-Welcke, Schwikal, Daus, \& Heinze, 2014; Rosselgong et al., 2018). Xylan/Polyvinyl alcohol nanofibers prepared by electrospinning possess interesting mechanical and rheological properties. This system was used to improve cardiac cell proliferation for the treatment of myocardial infarction (Soumya, Sajesh, Jayakumar, Nair, \& Chennazhi, 2012). Inulin-peptide conjugates self-assembled into micelles, that in response to inulinase, can degrade and release ornidazole, a drug for colon cancer and gastrointestinal disease (Shivhare et al., 2018). The mannose-rich guar gum possess extraordinary mucoadhesive properties and is used in combination with chitosan to form crosslinked hydrogels that serve as transdermal patches for sustained drug-release (Sami et al., 2018).

\section{Charged polysaccharides}

\section{Chitosan}

Chitin, poly $\beta-(1-4)-N$-acetylglucosamine, is the second most abundant polysaccharide in nature, mainly constructing exoskeleton of crustaceans, insects, and fungal cell wall. Despite of superior biocompatibility, biodegradability, and physical stability, chitin has been studied rarely for biomedical applications due to water insolubility. To overcome this drawback, chitin is treated with concentrated sodium hydroxide or chitin deacetylase to obtain chitosan, its partially deacetylated derivative (Figure 7). Chitosan is most important derivative of chitin, generally with a degree of acetylation (DA) lower than $50 \%$. The DA, distribution of amine and acetylamine groups, and molecular weight determines solubility and biological activity of chitosan (Aranaz et al., 2014). 


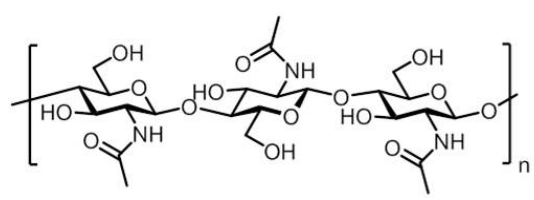

Chitin

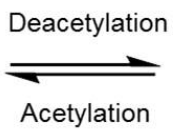

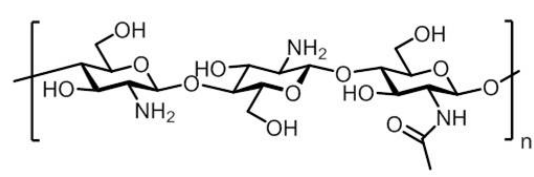

Chitosan

Figure 7: Chitin and its deacetylated analogue chitosan.

Similarly to cellulose, chitin forms strong inter- and intramolecular hydrogen bonds, which hamper its use. In addition, chitin possesses a fibril structure that cannot be solubilized in most organic solvents. Complex solvent mixtures, such as $\mathrm{CaCl}_{2} \cdot 2 \mathrm{H}_{2} \mathrm{O}$ saturated methanol, litium chloride/ $N, N$ dimethylacetamide ( $\mathrm{LiCl} / \mathrm{DMAc}$ ), $\mathrm{NaOH} /$ urea, hexafluoroisopropyl alcohol (HFIP), and ionic liquid are employed to disrupt the dense hydrogen bond network of chitin (Ifuku, 2014; Silva, Mano, \& Reis, 2017). Ultrafine nanofibers can be obtained by simple solvent evaporation from HFIP solutions or from precipitation induced by addition of water to a LiCl/DMAc solution. These nanofibers are important materials for tissue engineering, as confirmed by in vitro cell cytotoxicity and cell proliferation (Zhong et al., 2010). The chitin fibers prepared with HFIP were incorporated in gelatin methacryloyl, forming a ultrastrong and flexible hydrogel applicable in vascular tissue engineering (Hassanzadeh et al., 2016). Chitin solution in $\mathrm{CaCl}_{2} \cdot 2 \mathrm{H}_{2} \mathrm{O}$ saturated methanol forms colloidal nanogels, upon addition of excess methanol (Priya, Sabitha, \& Jayakumar, 2016). Chitin in $\mathrm{NaOH} /$ urea rapidly aggregated into nanofibrous microsphere with high cellular affinity (Duan et al., 2015).

Chitin has been chemically modified to obtain carboxymethyl chitin, glycol chitin, fluorinated chitin, and $N$ - and $O$ - sulfated chitin. All these modifications aim to improve the water solubility and mechanical properties of natural chitin (Rinaudo, 2006). The carboxymethyl chitin formed nanofiber with poly(vinyl alcohol) via electrospinning (Shalumon et al., 2009). The glycol chitin can easily generate thermosensitive hydrogels in PBS solution (Zhengzheng Li, Cho, Kwon, Janát-Amsbury, \& Huh, 2013). Like cellulose, chitin nanofibrils and nanowhiskers have attracted great attention as drug delivery scaffolds (Morganti et al., 2014; Ou, Zheng, Zhao, \& Liu, 2018). The most used chitin derivative is chitosan. As the only positively charged natural polysaccharide, chitosan has raised particular interest in biomedical nanotechnology. The positive charge provides antimicrobial, antibacterial, and anticoagulation properties and accelerates wound healing. The amino groups, that can be protonated in acidic conditions, permit to solubilize chitosan. Moreover, $\mathrm{pH}$-responsive systems can be easily created. Mucoadhesive properties and cell permeability are the most important features of this material, enhancing topical, ocular, nasal, and transdermal drug delivery efficiency. The positive charge allows for the adhesion of chitosan-materials to the highly negative mucous environment, through electrostatic interactions. Moreover, the interaction of chitosan with the negatively charged cell wall disrupts the phospholipid alignment and promotes cell penetration (Hamedi, Moradi, Hudson, \& Tonelli, 2018; Lin et al., 2018; M Ways, Lau, \& Khutoryanskiy, 2018). 

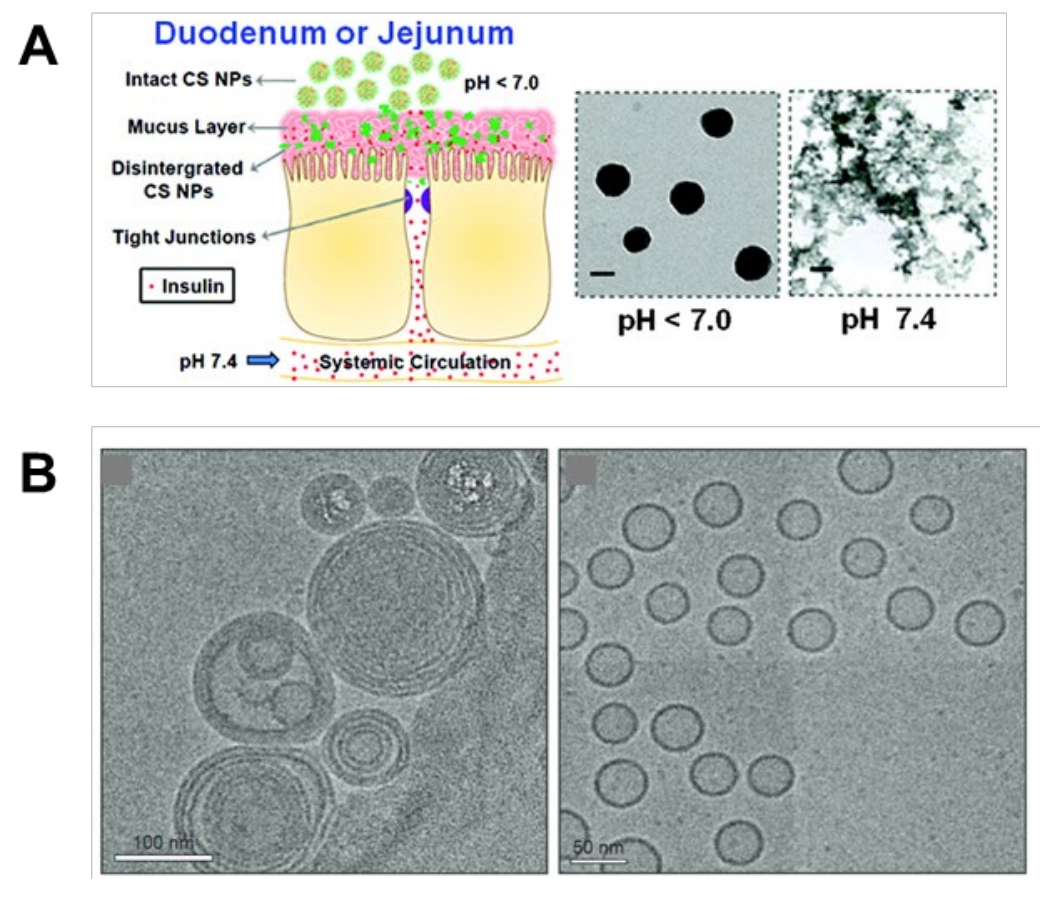

Figure 8: Chitosan nanoparticles for insulin delivery. (A) $\mathrm{pH}$-responsive nanoparticles shield with chitosan for oral delivery (Reprinted with permission from H. Sung et al. (2012). Copyright 2012 American Chemical Society). (B) Multilayered nanoparticles (left) and vesicles (right) encapsulating insulin with coassembly of chitosan and lecithin (Reprinted with permission from L. Liu et al. (2016). Copyright 2016 Dove Medical Press Limited).

The positively charged chitosan was co-assembled with negatively charged compounds, to afford different types of carrier systems (Quiñones, Peniche, \& Peniche, 2018). Co-assembly with negatively charged polymers, proteins, and polysaccharides has been tremendously exploited for the formation of drug delivery carriers, especially employed for insulin delivery (L. Liu, Zhou, Xia, \& Liu, 2016; Maciel, Yoshida, Pereira, Goycoolea, \& Franco, 2017; Sung, Sonaje, Liao, Hsu, \& Chuang, 2012; T. Wang, Hou, Su, Zhao, \& Shi, 2017; B. Xu et al., 2017)(Figure 8). A layer-by-layer approach, adding repetitively layers of opposite charged compounds one by one, permitted the formation of new materials (L. Li, Wang, et al., 2018).

Countless modifications have been introduced for cell targeting, stimuli responsiveness, and water solubility at neutral pH (C.-H. Chen, Lin, Wu, \& Mi, 2018; de Oliveira Pedro, Goycoolea, Pereira, Schmitt, \& Neumann, 2018; Lai \& Shum, 2015; B. Xu et al., 2017; T. Xu, Xu, Gu, Fang, \& Cao, 2018). Chitosan amphiphiles have been prepared by grafting hydrophilic and hydrophobic moieties onto the sugar backbone (J.-Y. Lee, Termsarasab, et al., 2017). Both the amine and/or the hydroxyl groups can be used to functionalize chitosan (Sahariah \& Másson, 2017). Three main strategies are used for chitosan functionalization: sulfaltion/sulfonation, amine quaternization, and carboxymethylation. Among them, carboxymethyl chitosan (CMCS), an amphiprotic biopolymer possessing both amine and carboxyl groups, may be the most promising biomedical material with outstanding chemical, physical and biological features. Different types of CMCS such as $\mathrm{N}$-CMCS, O-CMCS, N,N-CMCS, and N,O-CMCS are based on different substitution patterns. Each CMCS shows different water solubility and biological activity depending on the degree of carboxymethylation (Upadhyaya, Singh, Agarwal, \& Tewari, 2014). CMCS can be assembled into nanoparticles and hydrogels exploiting electrostatic interactions (AlRashida, Haider, Kortz, Joshi, \& Iqbal, 2018; Song et al., 2018). In particular, self-healing metal crosslinked CMCS hydrogels with high antibacterial activity can be used for tissue engineering and 
wound healing (Wahid et al., 2018). Several reviews provide a more detailed description of this topic (Shariatinia, 2018; Upadhyaya, Singh, Agarwal, \& Tewari, 2014).

Quaternized chitosan (QCS) in obtained by alkylation of the amines and/or grafting of quaternary ammonium groups to the hydroxyl groups. This functionalization results in permanent positive charges, independent from the $\mathrm{pH} . \mathrm{N}, \mathrm{N}, \mathrm{N}$-trimethyl chitosan chloride (TMCS) was the first chitosan derivative bearing $\mathrm{N}$-quaternized sites, showing interesting mucoadhesive properties (A. Martins et al., 2014). A TMCS nanoemulsion with dextran sulfate, prepared by hot high-pressure homogenization, successfully delivered a Parkinson's disease drug through the nasal mucosa (Pardeshi \& Belgamwar, 2018). TMCS can be additionally transformed to amphiphiles via $\mathrm{N}$ - and $O$-hydroxyalkylation. O-Alkyl TMCS nanomicelles, encapsulating peptide nucleic acid showed hemocompatability and a dramatic increase in cellular uptake (C. Liu, Wang, et al., 2018). Other types of QCS served as pH responsive nanocarriers (de Oliveira Pedro, Hoffmann, et al., 2018; Piras et al., 2018).

Sulfated and/or sulfonated chitosan (SCS) are heparin-like polysaccharides, mainly used for vascularization and bone tissue regeneration (Dimassi, Tabary, Chai, Blanchemain, \& Martel, 2018). Implants made of 2-N,6-O-sulfated chitosan based nanoparticles improved angiogenesis and bone formation with a rich vessel network (Cao, Wang, Hou, Xing, \& Liu, 2014). The same compound was used as a coating material for better blood circulation, constructing hierarchical structure with PLGA microsphere (Y. Yu et al., 2015). Glycyrrhetinic acid, a hydrophobic liver-targeting ligand, was attached to SCS and the resulting amphiphile was able to carry doxorubicin and suppress liver cancer (Tian et al., 2012).

\section{Glycosaminoglycans}

Glycosaminoglycans (GAGs) are large linear polysaccharides composed of a repeating disaccharide unit (usually an amino sugar and an uronic sugar) (Figure 9). The most common GAGs are hyaluronic acid or hyaluronan $\mathbf{1 7}$, chondroitin sulfate $\mathbf{1 8}$, dermatan sulfate $\mathbf{1 9}$, keratan sulfate $\mathbf{2 0}$, heparin and heparan sulfate 21. Except for hyaluronic acid, the amino and/or hydroxyl groups of GAGs are modified with $\mathrm{N}$ /O-sulfation, making the whole structure highly hydrophilic and negatively charged (Esko, Kimata, \& Lindahl, 2009). GAGs are widely present on the mammalian cell surface as well as in the extracellular matrix. For this reason, GAGs are popular materials for biomedical studies, as drugs or carriers in drug delivery systems (Fu, Suflita, \& Linhardt, 2016; G. Huang \& Huang, 2018; Köwitsch, Zhou, \& Groth, 2018; Rnjak-Kovacina, Tang, Whitelock, \& Lord, 2018; Rodriguez-Torres, Acosta-Torres, \& Diaz-Torres, 2018). 


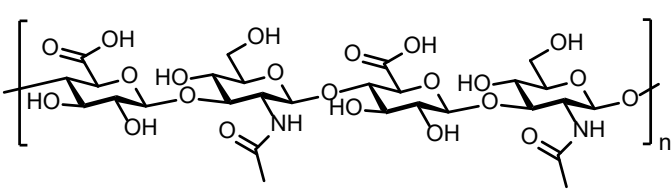

17. Hyaluronic acid (HA)

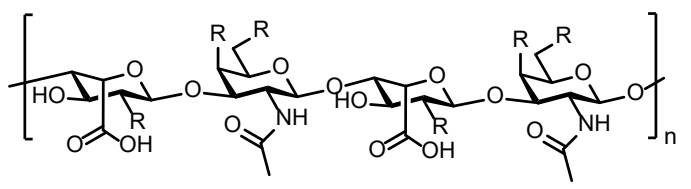

19. Dermatan sulfate (DS)

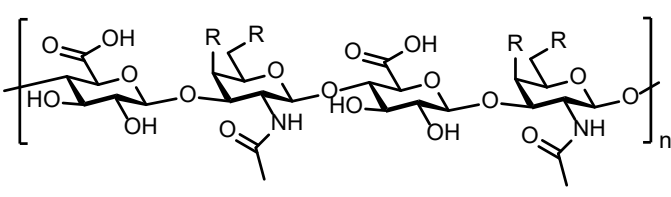

18. Chondroitin sulfate (ChS)

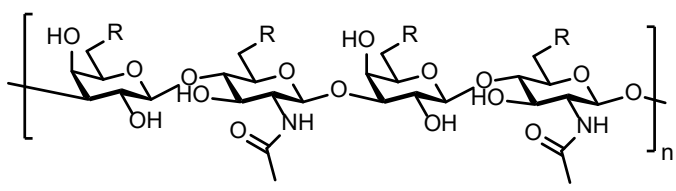

20. Keratan sulfate (KS)

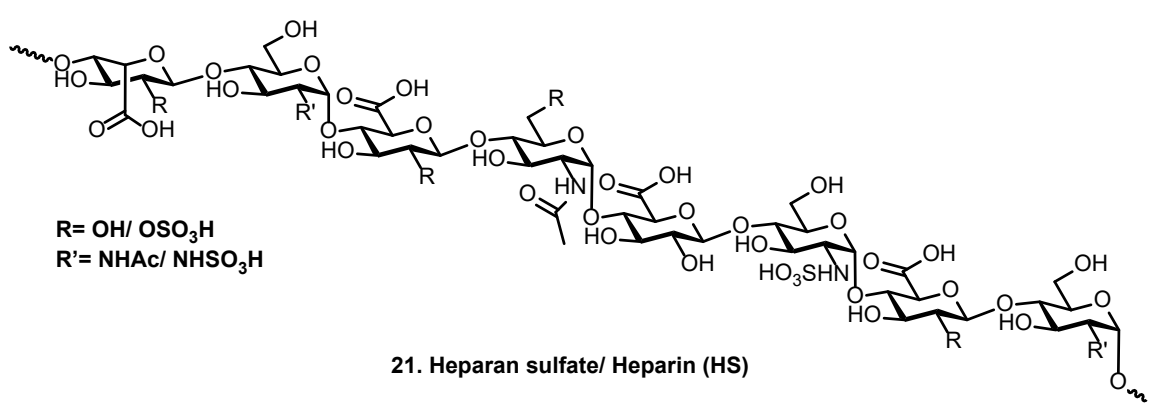

Figure 9: Structures of most common GAGs.

Unlike other polysaccharides, natural GAGs are highly charged, so they can directly serve as carriers for a verity of drugs, without further chemical modifications. Hyaluronic acid (HA)-based doxorubicin (DOX) delivery systems were fabricated through ion-interaction. Spherical nanoparticles (HA-NPs) were prepared from DOX and $\mathrm{HA}$ and further assembled into liposomal carriers with lipoid E80 and cholesterol, for CD44+ tumor-targeted delivery (W. Li, Yi, et al., 2016). Chondroitin sulfate (ChS)-nisin nanogel was prepared with different loading and morphology by electrostatic complexation (Mohtashamian, Boddohi, \& Hosseinkhani, 2018). Low molecular weight heparin-lappaconitine (LMWH-LA) delivery system was prepared through self-assembly, affording a pH-sensitive drug release (W. Sun et al., 2016). GAGs were co-assembled with positively charged proteins or polysaccharides (e.g chitosan), for clinical applications. Particularly relevant examples are hydrogels with tunable mechanical properties for cell therapy and tissue engineering (Alinejad, Adoungotchodo, Hui, Zehtabi, \& Lerouge, 2018), nanoparticles loading doxorubicin for anti-tumor therapy (C.-S. Hu, Tang, Chiang, et al., 2014), nanoparticles for ocular delivery of bromfenac sodium (Abdullah, Ibrahim, \& Warsi, 2016), pH responsible hydrogels for theophylline delivery (Lopes, Fajardo, Piai, Rubira, \& Muniz, 2013), and protein-loaded nanoparticles (Yeh, Cheng, Hu, Huang, \& Young, 2011).

The highly hydrophilic GAGs can be chemically modified with hydrophobic functionalities to create amphiphilic structures, expanding the horizons of GAG nanomaterials (Figure 10). Acetylated chondroitin sulfate, with a high degree of substitution, forms nanogels for DOX delivery (W. Park, Park, \& $\mathrm{Na}, 2010)$. Hydrophobic modifications on hyaluronic acid greatly affected its self-assembly manners as shown for the octadecylamine-modified HA that formed well-defined hydrophobic domains in its supramolecular structure (Payne, Svechkarev, Kyrychenko, \& Mohs, 2018). Oleyl hyaluronan carriers were designed for good skin penetration and large drug deposition in the dermis (Šmejkalová et al., 2017). Amphiphilic nanoparticles, with negatively charged surface, were prepared with a hyaluronic acid-decylamine (HA-DA) conjugates. This system can encapsulate budesonide (BDS) to treat the inflamed intestinal mucosa (Vafaei et al., 2016). Nanomicelles synthesized from hyaluronic acid, ethylenediamine (EDA), hexadecyl chains, polyethylene glycol (PEG), or L-carnitine (CRN) can be used 
as imatinib carriers, promoting transcorneal permeation (Bongiovì et al., 2018). Nanocarrier based on $\alpha$-linolenic acid ( $\alpha$ LNA)-grafted hyaluronan (HA) served to deliver hydrophobic drugs (Huerta-Angeles et al., 2016). In the same way, amphiphilic hyaluronan modified with $\omega$-phenylalkanoic ester showed potential applications for resveratrol and retinyl palmitate delivery (Matelová et al., 2016). Systems based on GAG/poly ( $D$, L-lactide-co-glycolide) were also employed for photodynamic therapy (Xiaoling Wang et al., 2018) and doxorubicin delivery (Hui Zhang et al., 2017). Several linkages were used for the amphiphilic functionalization. Spherical hyaluronic acid-doxorubicin particles, connected though hydrazone linkages (HA-hyd-DOX), were designed for acid-triggered release of doxorubicin (Liao et al., 2018). Fluorescein delivery systems, ChS-fluorescein-5-thiosemicarbazide (FTSC) were achieved by carbodiimide chemistry (Varghese, Liu, Sundaram, Hilborn, \& Oommen, 2016). HA-riboflavin (Rfv) delivery system was synthesized by click chemistry and used for the delivery of hydrophobic drugs such as dexamethasone, piroxicam and paclitaxel (Manzi et al., 2017). Chondroitin sulfate, directly linked with methotrexate (MTX), afforded a ChS nanogels with increased solubility and improved the delivery efficacy of MTX (J. Wang, Zhao, Chen, Qin, \& Zhu, 2017). Dihydroxyflavone-conjugated hyaluronic acid nanogels were prepared and tested for cellular uptake and antitumoral efficiency. The smaller nanogels were taken up by two kinds of tumor cells (HeLa and HepG2) (Choi et al., 2018). Adamantanegrafted hyaluronic acid can work as carrier for methyl- $\beta$-cyclodextrin through supramolecular assembly and proved to be a potential antitumor agent (Elamin, Yamashita, Higashi, Motoyama, \& Arima, 2018).

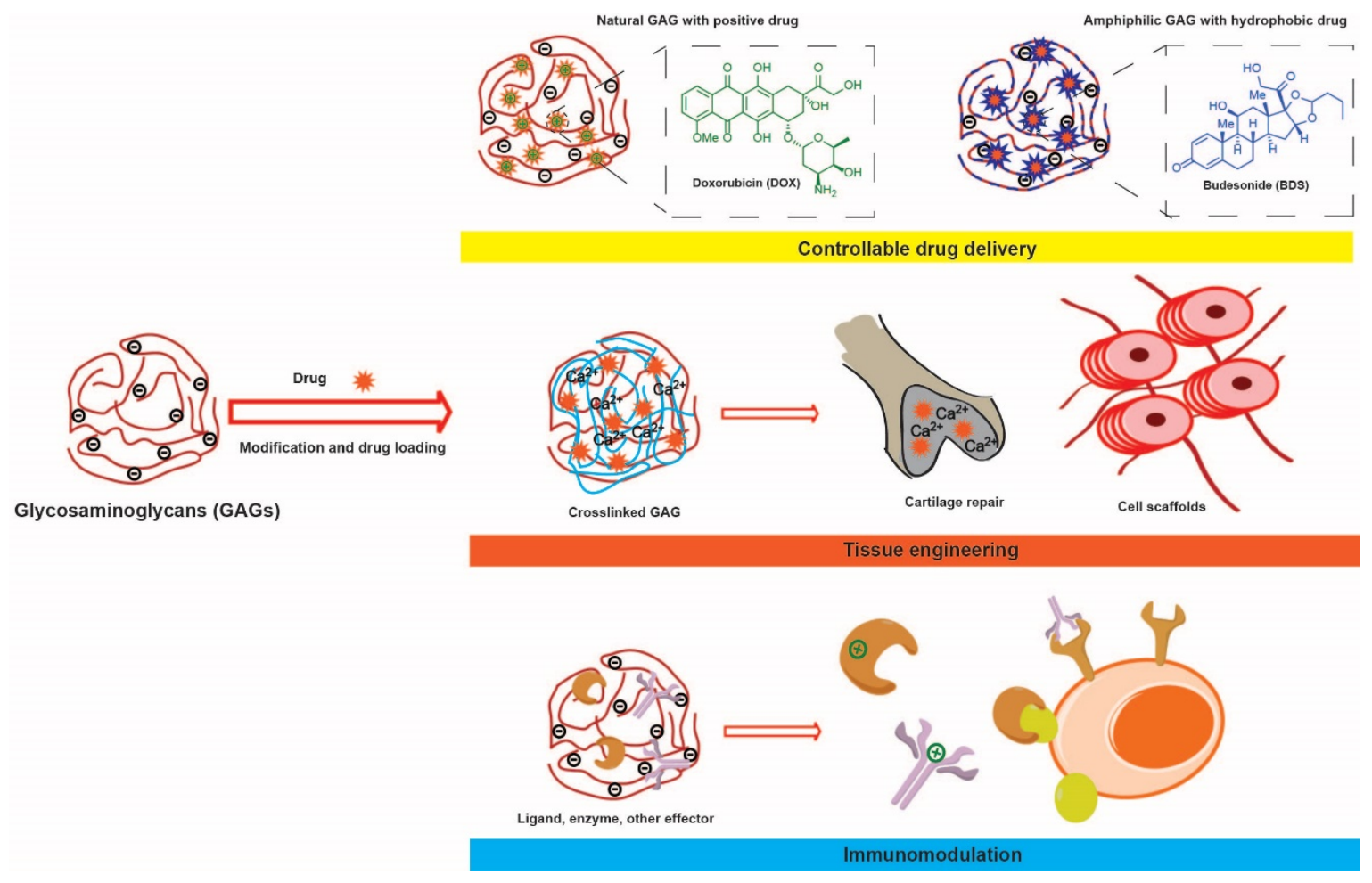

Figure 10: GAGs-based materials and their biomedical applications.

A common functionalization of GAGs is the introduction of disulfide bonds to prepare amphiphilic delivery systems with good biocompatibility and redox-responsive properties (Griesser, Hetényi, \& Bernkop-Schnürch, 2018). The conjugation of thiolated hydrophobic molecules to the HA side chain resulted in the formation of nanogels with good immunocompatibility and hemocompatibility (Pedrosa et al., 2016). Fluorescent hyaluronic acid-iodixanol nanogels (HAI-NGs) were used for targeted X-ray computed tomography (CT) imaging and chemotherapy (Y. Zhu et al., 2016). Nanomicelles with hyaluronic acid shell with disulfide-crosslinking were used for the treatment of 
multiple myeloma (Gu, Wang, Cheng, Cheng, \& Zhong, 2018). Several pH- and GSH-dual-sensitive polymeric conjugate were developed to deliver DOX (Debele, Yu, Yang, Shen, \& Lo, 2018; Yin et al., 2018). Redox-sensitive nanoparticles based on heparin- $\alpha$-tocopherol succinate (Hep-cys-TOS), formed nanoparticles used as carrier for paclitaxel (PTX) (Yang, Cai, Yu, Xi, \& Zhai, 2017).

Steroids (or derivatives) with hydrophobic fused ring systems, such as deoxycholic acid (DOCA), cholesterol, and glycyrrhetinic acid (GA), are widely used to fabricate amphiphilic GAG nanostructures. Reduction-sensitive micelles with disulfide linked GAG-DOCA structures were designed for triggered release of DOX (Yang et al., 2017) or docetaxel for the inhibition of metastasis and growth of melanoma (M. Liu, Du, et al., 2018). Spherical micelles with tunable size (124-237 nm) and redox-responsive properties were prepared from amphiphilic chondroitin sulfate-cholesterol conjugates and used as carriers for hydrophobic drugs (C. Yu et al., 2013). DOCA-heparin based micelles, with the pH-sensitive hydrazone bond between DOCA and DOX, enabled both antitumor and antimetastasis activities as well as drug delivery (Mei et al., 2016). Similar systems based on GAG/DOCA were developed in recent years: ChS-DOCA nanoparticles for DOX delivery (J.-Y. Lee, Chung, Cho, \& Kim, 2015a), HA-DOCAhistidine micelles for intracellular paclitaxel (PTX) delivery (Yanhua Liu, Zhou, Wang, et al., 2016), phenylboronic acid-decorated ChS-DOCA system for DOX delivery (J. Y. Lee, Chung, Cho, \& Kim, 2015b), ChS-DOCA/DOX nanoparticle for the therapy of CD44 receptor-expressing ovarian cancers (J.-Y. Lee et al., 2016), ChS-DOCA conjugates for docetaxel delivery (M. Liu, Du, \& Zhai, 2016).

Even though GAGs are highly negatively charged, several examples of functionalization with charged moieties are reported. An iRGD-heparin nanocarrier was synthesized by coupling the heparin backbone with $\mathrm{N}$-end cysteine peptide tumor-homing peptide iRGD. The system can be used as carrier for cis-diamminedichloroplatinum (II) delivery (Ai et al., 2018). A similar heparin-based drug delivery system was prepared by heparin-cis aconitic anhydride ligation. Paclitaxel (PTX) was grafted to the hydroxyl of heparin via an aconitic bond and served as $\mathrm{pH}$ sensitive spacer. Positively charged DOX and cationic folic acid (CFA) can be further loaded into the system via electrostatic interaction (Q. Li, Gan, et al., 2016). The amphiphilic chondroitin sulfate-histamine conjugate (ChS-his) can be synthesized and assembled into nanoparticles in aqueous medium and served as pH-sensitive carrier for DOX (C. Yu et al., 2014). Similarly, hybrid nanoparticles based on hyaluronic acid and poly (L-histidine) were used for diagnostic and therapeutic applications (S.-J. Lee \& Jeong, 2018).

Chemically and physically crosslinked GAGs possess unique properties in terms of biodegradation and biocompatibility. These features were used to form cell scaffolds, drug delivery systems, and for wound healing (Khunmanee, Jeong, \& Park, 2017). In addition, GAG-based hydrogels offer interesting possibilities for bioprinting (Martini et al., 2016). An injectable ionically cross-linked hydrogel was prepared via introduction of alginate to hyaluronate backbones, followed by addition of calcium ions. The gel proved effective in regenerating cartilage in a mouse model (H. Park, Woo, \& Lee, 2014). The $\mathrm{N}, \mathrm{O}$-carboxymethyl chitosan/fucoidan conjugate formed a three-dimensional hydrogel based on interconnected macropores, for bone tissue engineering ( $L u, L u, C h e n, L u, \& M i, 2018$ ). Other crosslinking methods for GAGs, such as urea-crosslinked HA systems (Fallacara et al., 2018), poly(ethylene glycol) crosslinked systems (Luo, Kirker, \& Prestwich, 2000; Shu, Liu, Palumbo, Luo, \& Prestwich, 2004), tyramine (TA) modified HA and ChS systems ( $\mathrm{Ni}$ et al., 2015) were also developed.

\section{Other charged polysaccharides}

In addition to the examples discussed above, several other polysaccharides are commonly used for biomedical materials development. Many of these polysaccharides are charged, highly hydrophilic 
glycans (Abedini, Ebrahimi, Roozbehani, Domb, \& Hosseinkhani, 2018). In particular, several marine polysaccharides are extracted and used for drug delivery applications (Cardoso, Costa, \& Mano, 2016). Carrageenan (CRG) is a highly sulphated linear polygalactan derivative with $\alpha$-D-galactose and $\beta$ 1,4/3,6-anhydro-galactose produced by rhodophyceae. Six classes of carrageenans, named Kappa ( $\mathrm{K}$ , lota(L)-, Lambda $(\lambda)-, \mathrm{Mu}(\mu)-, \mathrm{Nu}(\mathrm{v})$ - and Theta $(\theta)$, exist based on their different structures (Cunha \& Grenha, 2016). CRG hydrogels are popular choices for drug delivery, tissue engineering and wound healing (Yegappan, Selvaprithiviraj, Amirthalingam, \& Jayakumar, 2018). The preparation of microspherical $\mathrm{k}$-carrageenan gel particles, using emulsion technology, affects the final aerogel properties (Alnaief, Obaidat, \& Mashaqbeh, 2018; Obaidat, Alnaief, \& Mashaqbeh, 2018). kCRG-based drug carriers were developed (Obaidat et al., 2018; Sathuvan et al., 2017). Carboxymethylated Icarrageenan was chosen to deliver amphotericin B against the intracellular Candida glabrata infections (Aparna et al., 2018). Moreover, the combination of CRG with other polysaccharides was exploited for biomedical applications. Relevant examples are the cross-linked starch-k-carrageenan hydrogel for extended release of zaltoprofen (Sonawane \& Patil, 2018), the glucan/carrageenan hydrogels for wound healing (Nair, Raman, \& Doble, 2016), and the k-carrageenan/chitosan nanosystems for drug delivery (Amarnath Praphakar et al., 2017; Karimi, Mahdavinia, \& Massoumi, 2018; Mahdavinia, Mosallanezhad, Soleymani, \& Sabzi, 2017; Rochín-Wong et al., 2018).

Alginate (alginic acid) is a linear polysaccharide consisting of D-mannuronic acid and L-guluronic acid units, isolated from phaeophyceae (Tønnesen \& Karlsen, 2002), that was used the formation of several delivery systems. Moreover, injectable hydrogels of phosphorylated alginic acid-calcium complexes were developed for soft tissue engineering (H.-S. Kim, Song, Lee, \& Shin, 2015). Cross-linked alginate provides additional options to construct nanocarriers with different functions. The hydrophobically modified alginic acid, crosslinked by 1,10-decanediol, was proven to be a good carrier for ibuprofen (M. Wu et al., 2013). Similarly, albumin-crosslinked alginate hydrogels were prepared to deliver positively charged drugs (Tada, Tanabe, Tachibana, \& Yamauchi, 2007).

Ulvan, a cell-wall polysaccharide from green seaweeds, is mainly composed of a disaccharide repeating unit of uronic acid (D-glucuronic or L-ioduronic) and L-rhamnose-3-sulfate (Morelli \& Chiellini, 2010). Upon functionalization with methacryloyl moieties and photopolymerization, ulvan forms hydrogels used as matrix for cell encapsulation (Morelli \& Chiellini, 2010). A similar strategy was used to produce thermosensitive hydrogels (Morelli, Betti, Puppi, \& Chiellini, 2016) and scaffolds for bone tissue engineering (Dash et al., 2014). Lysozyme/ulvan complexes can be prepared through ionic interactions at physiological pH, showing good antibacterial activity (Tziveleka et al., 2018). Ulvan/chitosan systems were used as polymeric components of bone cements (Barros et al., 2013) and for the cultivation of osteoblasts (Toskas et al., 2012).

Plants also contain numerous useful polysaccharides for pharmaceutical applications. Pectin is one of the most structural complicated polysaccharides in nature; it is rich in galacturonic acid and contains different rare sugar units (Caffall \& Mohnen, 2009). Pectin is generally used in combination with other polysaccharides to produce materials for drug delivery. Bacterial cellulose-high methylated pectin films were developed to encapsulate and release biomacromolecules such as human serum albumin (Cacicedo et al., 2018). Alginate-pectin polymeric rafts showed pH-responsive property and showed potential for the treatment of gastro-esophageal reflux disorders (Hanif \& Abbas, 2018). Chitosan, due to its negative charge, was also widely used to prepare different nanostructures, in combination with pectin. Relevant examples are micelles based on self-assembling chitosan cross-linked pectindoxorubicin conjugates (Z.-P. Li, Jiang, et al., 2018), pectin-chitosan membrane scaffolds for the 
controlled stem cell adhesion and proliferation (J. G. Martins et al., 2018), and electrospun pectinoligochitosan nanofibers for tissue engineering (McCune et al., 2018).

Gum arabic from the Acacia senegal and Acacia seyal trees is a branched heteropolysaccharide with a 1, 3-linked $\beta$-D-galactopyranose backbone and L-arabinose, L-rhamnose, or D-glucuronic acid branching. It shows important biomedical properties, including antimicrobial, anti-inflammatory, and anticoagulant activity (Patel \& Goyal, 2015). Alginate-gum arabic hydrogels, crosslinked with $\mathrm{Ca}^{2+}$, showed potential applications for wound healing (M. Li, Li, et al., 2017). Additionally, pH-sensitive delivery systems were obtained from the cross-linking of carboxymethyl chitosan-gum Arabic (G.-Q. Huang, Cheng, Xiao, Wang, \& Han, 2016).

Gellan gum is a bacterial extracellular polysaccharide secreted by Pseudomonas elodea, which contain a tetrasaccharide repeating unit with $\alpha$-L-rhamnose, $\beta$-D-glucuronic acid, and two $\beta$-D-glucoses (Osmałek, Froelich, \& Tasarek, 2014). It was used in ocular delivery systems (Paolicelli et al., 2018; J. Sun \& Zhou, 2018), cutaneous delivery systems (Musazzi et al., 2018), and for antibiotic delivery during wound healing (Shukla \& Shukla, 2018). Additionally, oxygen-producing biomaterials were developed based on gellan gum (Newland et al., 2017). Chitosan-gellan gum systems (S. Kumar, Kaur, Bernela, Rani, \& Thakur, 2016), and pectin-gellan gum systems (Bera, Kumar, \& Maiti, 2018; Fernandes, Fortes, da Cruz Fonseca, Breitkreutz, \& Ferraz, 2018; Prezotti et al., 2018) are popular choices for smart drug delivery systems. Xanthan gum is a microbial polysaccharide produced by Xanthomonas bacteria; it is negatively charged and widely used for tissue engineering (A. Kumar, Rao, \& Han, 2018) and drug delivery (Salamanca, Yarce, Moreno, Prieto, \& Recalde, 2018). Xanthan gum-chitosan nanofibers (Shekarforoush, Ajalloueian, Zeng, Mendes, \& Chronakis, 2018), gellan-xanthan systems (Ramburrun, Kumar, Choonara, du Toit, \& Pillay, 2017; Sehgal, Roohani-Esfahani, Zreiqat, \& Banerjee, 2017), and xanthan gum hydrogels perform great in biomedical applications (Ruquan Zhang et al., 2018).

\section{Conclusion}

Due to their natural abundance and tendency to form supramolecular networks, carbohydrates are important substrates for biomedical applications. Several materials, based on simple monosaccharides or complex polymers have been synthesized. Tunable properties can be achieved through chemical modifications as well as assembly conditions. A plethora of morphologies, from spherical particles to nanogels, can be obtained. Due to their biocompatibility, those materials found several applications in drug delivery and tissue engineering. Recently, the attention has been directed to the formation of responsive drug delivery systems. Very stable assemblies have been developed, that are able to target particular cells and decompose in response to external stimuli, such as $\mathrm{pH}$ or salt concentration, to release the cargo. Similarly, the reversible association of carbohydrate-based nanomaterials is particularly useful for implants and tissue engineering.

The variety of natural carbohydrates, from monosaccharides, to cyclic systems, as well as long charged or neutral polymers has given rise to a range of materials with tunable properties. Chemical modifications have further expanded the range of applications. Reproducibility is the main challenge in the carbohydrate materials field. Polysaccharides are generally extracted from natural sources, often in low purity and high polydispersity. Control on the degree of substitution and polymerization are serious challenges that have to be addressed, in order to achieve more reproducible results. Moreover, a deeper understanding of how to regioselectively modified natural polysaccharides is needed. Purely synthetic, well-defined systems are limited to mono- and disaccharides. With the development of synthetic techniques that allow for quick access to longer oligosaccharides, new 
glycomaterials can be envisioned. Well-defined derivatives will help to establish the relationship between polysaccharide structure and its assembling behavior, opening the way to novel and reproducible biomedical applications.

\section{Acknowledgments}

We thank the Max-Planck Society, the Minerva-Fast-Track Program, and the MPG-FhG Cooperation Project Glyco3Display for generous financial support.

\section{References}

A. Varki; R. Cummings; J. Esko; H. Freeze; P. Stanley; G. Hart; P.H. Seeberger. (2017). Essentials of glycobiology (3rd ed.). Cold Spring Harbor, N.Y.: Cold Spring Harbor Laboratory Press.

Abdullah, T. A., Ibrahim, N. J., \& Warsi, M. H. (2016). Chondroitin sulfate-chitosan nanoparticles for ocular delivery of bromfenac sodium: Improved permeation, retention, and penetration. International journal of pharmaceutical investigation, 6(2), 96.

Abedini, F., Ebrahimi, M., Roozbehani, A. H., Domb, A. J., \& Hosseinkhani, H. (2018). Overview on natural hydrophilic polysaccharide polymers in drug delivery. Polymers for Advanced Technologies, 29(10), 2564-2573.

Agarwal, T., Narayana, S. G. H., Pal, K., Pramanik, K., Giri, S., \& Banerjee, I. (2015). Calcium alginatecarboxymethyl cellulose beads for colon-targeted drug delivery. International journal of biological macromolecules, 75, 409-417.

Ai, S., Zhen, S., Liu, Z., Sun, F., He, X., Chu, F., . . Wang, J. (2018). An iRGD peptide conjugated heparin nanocarrier for gastric cancer therapy. RSC Advances, 8(52), 30012-30020.

Al-Rashida, M., Haider, A., Kortz, U., Joshi, S. A., \& Iqbal, J. (2018). Development and in vitro anticancer evaluation of self-assembled supramolecular $\mathrm{pH}$ responsive hydrogels of carboxymethyl chitosan and polyoxometalate. ChemistrySelect, 3(5), 1472-1479.

Alinejad, Y., Adoungotchodo, A., Hui, E., Zehtabi, F., \& Lerouge, S. (2018). An injectable chitosan/chondroitin sulfate hydrogel with tunable mechanical properties for cell therapy/tissue engineering. International journal of biological macromolecules, 113, 132-141.

Alnaief, M., Obaidat, R., \& Mashaqbeh, H. (2018). Effect of processing parameters on preparation of carrageenan aerogel microparticles. Carbohydrate Polymers, 180, 264-275.

Amalraj, A., Gopi, S., Thomas, S., \& Haponiuk, J. T. (2018). Cellulose nanomaterials in biomedical, food, and nutraceutical applications: a review. Paper presented at the Macromolecular Symposia.

Amarnath Praphakar, R., Alarfaj, A. A., Munusamy, M. A., Dusthackeer, V. N. A., Kumar Subbiah, S., \& Rajan, M. (2017). Phosphorylated K-carrageenan-facilitated chitosan nanovehicle for sustainable anti-tuberculosis multi drug delivery. ChemistrySelect, 2(24), 7100-7107.

Aparna, V., Melge, A. R., Rajan, V., Biswas, R., Jayakumar, R., \& Mohan, C. G. (2018). Carboxymethylated l-carrageenan conjugated amphotericin B loaded gelatin nanoparticles for treating intracellular Candida glabrata infections. International journal of biological macromolecules, 110, 140-149.

Aranaz, I., Mengíbar, M., Harris, R., Miralles, B., Acosta, N., Calderón, L., . . Heras, Á. (2014). Role of physicochemical properties of chitin and chitosan on their functionality. Current Chemical Biology, 8(1), 27-42.

Azzam, T., Eliyahu, H., Makovitzki, A., \& Domb, A. (2003). Dextran-spermine conjugate: an efficient vector for gene delivery. Paper presented at the Macromolecular Symposia. 
Bachelder, E. M., Beaudette, T. T., Broaders, K. E., Dashe, J., \& Fréchet, J. M. (2008). Acetal-derivatized dextran: an acid-responsive biodegradable material for therapeutic applications. Journal of the American Chemical Society, 130(32), 10494-10495.

Bachelder, E. M., Beaudette, T. T., Broaders, K. E., Fréchet, J. M., Albrecht, M. T., Mateczun, A. J., . . . Keane-Myers, A. M. (2010). In vitro analysis of acetalated dextran microparticles as a potent delivery platform for vaccine adjuvants. Molecular pharmaceutics, 7(3), 826-835.

Bachelder, E. M., Pino, E. N., \& Ainslie, K. M. (2016). Acetalated dextran: a tunable and acid-labile biopolymer with facile synthesis and a range of applications. Chemical Reviews, 117(3), 19151926.

Barkhordari, S., Yadollahi, M., \& Namazi, H. (2014). pH sensitive nanocomposite hydrogel beads based on carboxymethyl cellulose/layered double hydroxide as drug delivery systems. Journal of Polymer Research, 21(6), 454.

Barros, A., Alves, A., Nunes, C., Coimbra, M. A., Pires, R., \& Reis, R. (2013). Carboxymethylation of ulvan and chitosan and their use as polymeric components of bone cements. Acta biomaterialia, 9(11), 9086-9097.

Bellia, F., La Mendola, D., Pedone, C., Rizzarelli, E., Saviano, M., \& Vecchio, G. (2009). Selectively functionalized cyclodextrins and their metal complexes. Chemical Society Reviews, 38(9), 2756-2781.

Bera, H., Kumar, S., \& Maiti, S. (2018). Facile synthesis and characterization of tailor-made pectin-gellan gum-bionanofiller composites as intragastric drug delivery shuttles. International journal of biological macromolecules, 118, 149-159.

Bisht, S., \& Maitra, A. (2009). Dextran-doxorubicin/chitosan nanoparticles for solid tumor therapy. Wiley Interdisciplinary Reviews: Nanomedicine and Nanobiotechnology, 1(4), 415-425.

Bongiovì, F., Fiorica, C., Palumbo, F. S., Di Prima, G., Giammona, G., \& Pitarresi, G. (2018). Imatinibloaded micelles of hyaluronic acid derivatives for potential treatment of neovascular ocular diseases. Molecular pharmaceutics, 15(11), 5031-5045.

Braz, L., Grenha, A., Corvo, M. C., Lourenço, J. P., Ferreira, D., Sarmento, B., \& da Costa, A. M. R. (2018). Synthesis and characterization of Locust Bean Gum derivatives and their application in the production of nanoparticles. Carbohydrate Polymers, 181, 974-985.

Broaders, K. E., Cohen, J. A., Beaudette, T. T., Bachelder, E. M., \& Fréchet, J. M. (2009). Acetalated dextran is a chemically and biologically tunable material for particulate immunotherapy. Proceedings of the National Academy of Sciences, 106(14), 5497-5502.

Cacicedo, M. L., Islan, G. A., Drachemberg, M. F., Alvarez, V. A., Bartel, L. C., Bolzán, A. D., \& Castro, G. R. (2018). Hybrid bacterial cellulose-pectin films for delivery of bioactive molecules. New Journal of Chemistry, 42(9), 7457-7467.

Caffall, K. H., \& Mohnen, D. (2009). The structure, function, and biosynthesis of plant cell wall pectic polysaccharides. Carbohydrate research, 344(14), 1879-1900.

Cámara, C. I., Lurgo, F. E., Fanani, M. L., \& Wilke, N. (2018). Mechanical stability of lipid membranes decorated with dextran sulfate. ACS Omega, 3(9), 11673-11683.

Cao, L., Wang, J., Hou, J., Xing, W., \& Liu, C. (2014). Vascularization and bone regeneration in a critical sized defect using 2-N, 6-O-sulfated chitosan nanoparticles incorporating BMP-2. Biomaterials, 35(2), 684-698.

Capanema, N. S., Mansur, A. A., Carvalho, S. M., Carvalho, I. C., Chagas, P., de Oliveira, L. C. A., \& Mansur, H. S. (2018). Bioengineered carboxymethyl cellulose-doxorubicin prodrug hydrogels for topical chemotherapy of melanoma skin cancer. Carbohydrate Polymers, 195, 401-412.

Cardoso, M. J., Costa, R. R., \& Mano, J. F. (2016). Marine origin polysaccharides in drug delivery systems. Marine drugs, 14(2), 34.

Celebioglu, A., \& Uyar, T. (2012). Electrospinning of nanofibers from non-polymeric systems: polymerfree nanofibers from cyclodextrin derivatives. Nanoscale, 4(2), 621-631.

Celebioglu, A., \& Uyar, T. (2013a). Electrospinning of nanofibers from non-polymeric systems: Electrospun nanofibers from native cyclodextrins. Journal of colloid and interface science, 404, 1-7. 
Celebioglu, A., \& Uyar, T. (2013b). Electrospun gamma-cyclodextrin ( $\gamma$-CD) nanofibers for the entrapment of volatile organic compounds. RSC Advances, 3(45), 22891-22895.

Chabre, Y. M., \& Roy, R. (2013). Multivalent glycoconjugate syntheses and applications using aromatic scaffolds. Chemical Society Reviews, 42(11), 4657-4708.

Chai, Y. H., Feng, Y. L., Wu, J. J., Deng, C. Q., Liu, A. Y., \& Zhang, Q. (2017). Recyclable benzyl-type fluorous tags: Preparation and application in oligosaccharide synthesis. Chinese Chemical Letters 28(8), 1693-1700.

Challa, R., Ahuja, A., Ali, J., \& Khar, R. (2005). Cyclodextrins in drug delivery: an updated review. Aaps Pharmscitech, 6(2), E329-E357.

Chang, C., He, M., Zhou, J., \& Zhang, L. (2011). Swelling behaviors of pH-and salt-responsive cellulosebased hydrogels. Macromolecules, 44(6), 1642-1648.

Chen, A., Okafor, I. S., Garcia, C., \& Wang, G. (2018). Synthesis and self-assembling properties of 4,6O-benzylidene acetal protected D-glucose and D-glucosamine beta-1,2,3-triazole derivatives. Carbohydrate research, 461, 60-75.

Chen, C.-H., Lin, Y.-S., Wu, S.-J., \& Mi, F.-L. (2018). Mutlifunctional nanoparticles prepared from arginine-modified chitosan and thiolated fucoidan for oral delivery of hydrophobic and hydrophilic drugs. Carbohydrate Polymers, 193, 163-172.

Chen, Z., Krishnamachary, B., Penet, M.-F., \& Bhujwalla, Z. M. (2018). Acid-degradable dextran as an image guided siRNA carrier for COX-2 downregulation. Theranostics, 8(1), 1.

Choi, Y. R., Kim, H.-J., Ahn, G. Y., Lee, M. J., Park, J. R., Jun, D.-R., . . Choi, S.-W. (2018). Fabrication of dihydroxyflavone-conjugated hyaluronic acid nanogels for targeted antitumoral effect. Colloids Surfaces B: Biointerfaces, 171, 690-697.

Clemente, M. J., Romero, P., Serrano, J. L., Fitremann, J., \& Oriol, L. (2012). Supramolecular hydrogels based on glycoamphiphiles: effect of the disaccharide polar head. Chemistry of Materials, 24(20), 3847-3858.

Cohen, J. A., Beaudette, T. T., Cohen, J. L., Broaders, K. E., Bachelder, E. M., \& Fréchet, J. M. (2010). Acetal-modified dextran microparticles with controlled degradation kinetics and surface functionality for gene delivery in phagocytic and non-phagocytic cells. Advanced materials, 22(32), 3593-3597.

Cohen, J. L., Schubert, S., Wich, P. R., Cui, L., Cohen, J. A., Mynar, J. L., \& Fréchet, J. M. (2011). Aciddegradable cationic dextran particles for the delivery of siRNA therapeutics. Bioconjugate chemistry, 22(6), 1056-1065.

Crini, G. (2014). Review: a history of cyclodextrins. Chemical Reviews, 114(21), 10940-10975.

Cumpstey, I. (2013). Chemical modification of polysaccharides ISRN Organic Chemistry, 2013, 27.

Cunha, L., \& Grenha, A. (2016). Sulfated seaweed polysaccharides as multifunctional materials in drug delivery applications. Marine drugs, 14(3), 42.

Dai, L., Liu, K.-F., Si, C.-L., He, J., Lei, J.-D., \& Guo, L.-Q. (2015). A novel self-assembled targeted nanoparticle platform based on carboxymethylcellulose co-delivery of anticancer drugs. Journal of Materials Chemistry B, 3(32), 6605-6617.

Dai, L., \& Si, C.-L. (2017). Cellulose-graft-poly (methyl methacrylate) nanoparticles with high biocompatibility for hydrophobic anti-cancer drug delivery. Materials Letters, 207, 213-216.

Dash, M., Samal, S. K., Bartoli, C., Morelli, A., Smet, P. F., Dubruel, P., . . . interfaces. (2014). Biofunctionalization of ulvan scaffolds for bone tissue engineering. ACS applied materials interfaces, 6(5), 3211-3218.

Davis, M. E., \& Brewster, M. E. (2004). Cyclodextrin-based pharmaceutics: past, present and future. Nature reviews Drug discovery, 3(12), 1023.

De Carvalho, L., Peres, B. U., Maezomo, H., Shen, Y., Haapasalo, M., Manso, A., . . Carvalho, R. (2017). Chlorhexidine-containing electrospun nanofibers: Effect of production mode on chlorhexidine release. Dental Materials, 33, e17-e18.

de Oliveira Pedro, R., Goycoolea, F. M., Pereira, S., Schmitt, C. C., \& Neumann, M. G. (2018). Synergistic effect of quercetin and $\mathrm{pH}$-responsive DEAE-chitosan carriers as drug delivery system for breast cancer treatment. International journal of biological macromolecules, 106, 579-586. 
de Oliveira Pedro, R., Hoffmann, S., Pereira, S., Goycoolea, F. M., Schmitt, C. C., \& Neumann, M. G. (2018). Self-assembled amphiphilic chitosan nanoparticles for quercetin delivery to breast cancer cells. European Journal of Pharmaceutics, 131, 203-210.

Debele, T. A., Mekuria, S. L., \& Tsai, H.-C. (2016). Polysaccharide based nanogels in the drug delivery system: Application as the carrier of pharmaceutical agents. Materials Science and Engineering: C, 68, 964-981.

Debele, T. A., Yu, L.-Y., Yang, C.-S., Shen, Y.-A., \& Lo, C.-L. (2018). pH-and GSH-sensitive hyaluronic acidMP conjugate micelles for intracellular delivery of doxorubicin to colon cancer cells and cancer stem cells. Biomacromolecules, 19(9), 3725-3737.

Del Valle, E. M. (2004). Cyclodextrins and their uses: a review. Process biochemistry, 39(9), 1033-1046. Delbianco, M., Bharate, P., Varela-Aramburu, S., \& Seeberger, P. H. (2016). Carbohydrates in supramolecular chemistry. Chemical Reviews, 116(4), 1693-1752.

Dimassi, S., Tabary, N., Chai, F., Blanchemain, N., \& Martel, B. (2018). Sulfonated and sulfated chitosan derivatives for biomedical applications: A review. Carbohydrate Polymers, 202, 382-396.

Dong, Y., Lu, X., Wang, P., Liu, W., Zhang, S., Wu, Z., \& Chen, H. (2018). Facile fabrication of a "Catch and Release" cellulose acetate nanofiber interface: a platform for reversible glycoprotein capture and bacterial attachment. Journal of Materials Chemistry B, 6(42), 6744-6751.

Duan, B., Zheng, X., Xia, Z., Fan, X., Guo, L., Liu, J., .. . Zhang, L. (2015). Highly biocompatible nanofibrous microspheres self-assembled from chitin in $\mathrm{NaOH} /$ urea aqueous solution as cell carriers. Angewandte Chemie International Edition, 54(17), 5152-5156.

Dufour, G., Bigazzi, W., Wong, N., Boschini, F., De Tullio, P., Piel, G., . . . Evrard, B. (2015). Interest of cyclodextrins in spray-dried microparticles formulation for sustained pulmonary delivery of budesonide. International journal of pharmaceutics, 495(2), 869-878.

Elamin, K. M., Yamashita, Y., Higashi, T., Motoyama, K., \& Arima, H. (2018). Supramolecular complex of methyl- $\beta$-cyclodextrin with adamantane-grafted hyaluronic acid as a novel antitumor agent. Chemical Pharmaceutical Bulletin, 66(3), 277-285.

Esko, J. D., Kimata, K., \& Lindahl, U. (2009). Essentials of glycobiology: Chapter 17 Proteoglycans and sulfated glycosaminoglycans. Cold Spring Harbor, N.Y.: Cold Spring Harbor Laboratory Press.

Evrard, B., Bertholet, P., Guéders, M., Flament, M.-P., Piel, G., Delattre, L., . . Cataldo, D. (2004). Cyclodextrins as a potential carrier in drug nebulization. Journal of Controlled Release, 96(3), 403-410.

Fallacara, A., Busato, L., Pozzoli, M., Ghadiri, M., Ong, H. X., Young, P. M., . . Traini, D. (2018). Combination of urea-crosslinked hyaluronic acid and sodium ascorbyl phosphate for the treatment of inflammatory lung diseases: An in vitro study. European Journal of Pharmaceutical Sciences, 120, 96-106.

Fasting, C., Schalley, C. A., Weber, M., Seitz, O., Hecht, S., Koksch, B., . . Haag, R. (2012). Multivalency as a chemical organization and action principle. Angewandte Chemie, International Edition, 51(42), 10472-10498.

Fernandes, F. P., Fortes, A. C., da Cruz Fonseca, S. G., Breitkreutz, J., \& Ferraz, H. G. (2018). Manufacture and characterization of mucoadhesive buccal films based on pectin and gellan gum containing triamcinolone acetonide. International Journal of Polymer Science, 2018.

Ferreira, L., Gil, M. H., \& Dordick, J. S. (2002). Enzymatic synthesis of dextran-containing hydrogels. Biomaterials, 23(19), 3957-3967.

Ferreira, M. P., Talman, V., Torrieri, G., Liu, D., Marques, G., Moslova, K., ... Ruskoaho, H. (2018). Dualdrug delivery using dextran-functionalized nanoparticles targeting cardiac fibroblasts for cellular reprogramming. Advanced Functional Materials, 28(15), 1705134.

Fischer, S., Thümmler, K., Volkert, B., Hettrich, K., Schmidt, I., \& Fischer, K. (2008). Properties and applications of cellulose acetate. Paper presented at the Macromolecular Symposia.

Fox, S. C., Li, B., Xu, D., \& Edgar, K. J. (2011). Regioselective esterification and etherification of cellulose: a review. Biomacromolecules, 12(6), 1956-1972.

Fu, L., Suflita, M., \& Linhardt, R. J. (2016). Bioengineered heparins and heparan sulfates. Advanced Drug Delivery Reviews, 97, 237-249. 
Gallovic, M. D., Schully, K. L., Bell, M. G., Elberson, M. A., Palmer, J. R., Darko, C. A., . . Ainslie, K. M. (2016). Acetalated dextran microparticulate vaccine formulated via coaxial electrospray preserves toxin neutralization and enhances murine survival following inhalational Bacillus anthracis exposure. Advanced healthcare materials, 5(20), 2617-2627.

Gao, W., Liu, Y., Jing, G., Li, K., Zhao, Y., Sha, B., . . Wu, D. (2017). Rapid and efficient crossing bloodbrain barrier: Hydrophobic drug delivery system based on propionylated amylose helix nanoclusters. Biomaterials, 113, 133-144.

Garcia-Vaquero, M., Rajauria, G., O'Doherty, J. V., \& Sweeney, T. (2017). Polysaccharides from macroalgae: Recent advances, innovative technologies and challenges in extraction and purification. Food Research International, 99, 1011-1020.

George, A., Shah, P. A., \& Shrivastav, P. (2018). Guar gum: Versatile natural polymer for drug delivery applications. European Polymer Journal.

Giglio, V., Viale, M., Bertone, V., Maric, I., Vaccarone, R., \& Vecchio, G. (2018). Cyclodextrin polymers as nanocarriers for sorafenib. Investigational new drugs, 36(3), 370-379.

González-Gaitano, G., Rodriguez, P., Isasi, J., Fuentes, M., Tardajos, G., \& Sánchez, M. (2002). The aggregation of cyclodextrins as studied by photon correlation spectroscopy. Journal of inclusion phenomena and macrocyclic chemistry, 44(1-4), 101-105.

Gopinath, V., Saravanan, S., Al-Maleki, A. R., Ramesh, M., \& Vadivelu, J. (2018). A review of natural polysaccharides for drug delivery applications: Special focus on cellulose, starch and glycogen. Biomedicine \& Pharmacotherapy, 107, 96-108.

Gour, N., Purohit, C. S., Verma, S., Puri, R., \& Ganesh, S. (2009). Mannosylated self-assembled structures for molecular confinement and gene delivery applications. Biochemical and Biophysical Research Communications, 378(3), 503-506.

Griesser, J., Hetényi, G., \& Bernkop-Schnürch, A. (2018). Thiolated hyaluronic acid as versatile Mucoadhesive polymer: from the chemistry behind to product developments-what are the capabilities? Polymers, 10(3), 243.

Gu, Z., Wang, X., Cheng, R., Cheng, L., \& Zhong, Z. (2018). Hyaluronic acid shell and disulfide-crosslinked core micelles for in vivo targeted delivery of bortezomib for the treatment of multiple myeloma. Acta biomaterialia, 80, 288-295.

Guan, X., Fan, K., Gao, T., Ma, A., Zhang, B., \& Song, J. (2016). A novel multi-stimuli responsive gelator based on D-gluconic acetal and its potential applications. Chemical Communications, 52(5), 962-965.

Guo, Y., Wang, X., Shu, X., Shen, Z., \& Sun, R.-C. (2012). Self-assembly and paclitaxel loading capacity of cellulose-graft-poly (lactide) nanomicelles. Journal of agricultural and food chemistry, 60(15), 3900-3908.

Hahm, H. S., Schlegel, M. K., Hurevich, M., Eller, S., Schuhmacher, F., Hofmann, J., . . Seeberger, P. H. (2017). Automated glycan assembly using the Glyconeer 2.1 synthesizer. Proceedings of the National Academy of Sciences, 114(17), E3385-E3389.

Hamedi, H., Moradi, S., Hudson, S. M., \& Tonelli, A. E. (2018). Chitosan based hydrogels and their applications for drug delivery in wound dressings: A review. Carbohydrate Polymers, 199, 445460.

Hanif, M., \& Abbas, G. (2018). pH-responsive alginate-pectin polymeric rafts and their characterization. Advances in Polymer Technology, 37(5), 1496-1506.

Harata, K. (1998). Structural aspects of stereodifferentiation in the solid state. Chemical Reviews, 98(5), 1803-1828.

Hassanzadeh, P., Kazemzadeh-Narbat, M., Rosenzweig, R., Zhang, X., Khademhosseini, A., Annabi, N., \& Rolandi, M. (2016). Ultrastrong and flexible hybrid hydrogels based on solution self-assembly of chitin nanofibers in gelatin methacryloyl (GelMA). Journal of Materials Chemistry $B, 4(15)$, 2539-2543.

He, S., Cong, Y., Zhou, D., Li, J., Xie, Z., Chen, X., .. Huang, Y. (2015). A dextran-platinum (iv) conjugate as a reduction-responsive carrier for triggered drug release. Journal of Materials Chemistry $B$, 3(41), 8203-8211. 
Heo, R., You, D. G., Um, W., Choi, K. Y., Jeon, S., Park, J.-S., . . Kwon, I. C. (2017). Dextran sulfate nanoparticles as a theranostic nanomedicine for rheumatoid arthritis. Biomaterials, 131, 1526.

Hoang, B., Ernsting, M. J., Roy, A., Murakami, M., Undzys, E., \& Li, S.-D. (2015). Docetaxelcarboxymethylcellulose nanoparticles target cells via a SPARC and albumin dependent mechanism. Biomaterials, 59, 66-76.

Hu, C.-S., Tang, S.-L., Chiang, C.-H., Hosseinkhani, H., Hong, P.-D., \& Yeh, M.-K. (2014). Characterization and anti-tumor effects of chondroitin sulfate-chitosan nanoparticles delivery system. Journal of nanoparticle research, 16(11), 2672.

Hu, H., Li, Y., Zhou, Q., Ao, Y., Yu, C., Wan, Y., . . Yang, X. (2016). Redox-sensitive hydroxyethyl starchdoxorubicin conjugate for tumor targeted drug delivery. ACS applied materials interfaces, 8(45), 30833-30844.

Hu, J., Seeberger, P. H., \& Yin, J. (2016). Using carbohydrate-based biomaterials as scaffolds to control human stem cell fate. Organic \& Biomolecular Chemistry, 14(37), 8648-8658.

Hu, Q. D., Tang, G. P., \& Chu, P. K. (2014). Cyclodextrin-based host-guest supramolecular nanoparticles for delivery: from design to applications. Accounts of Chemical Research, 47(7), 2017-2025.

Huang, G.-Q., Cheng, L.-Y., Xiao, J.-X., Wang, S.-Q., \& Han, X.-N. (2016). Genipin-crosslinked Ocarboxymethyl chitosan-gum Arabic coacervate as a $\mathrm{pH}$-sensitive delivery system and microstructure characterization. Journal of biomaterials applications, 31(2), 193-204.

Huang, G., \& Huang, H. (2018). Application of hyaluronic acid as carriers in drug delivery. Drug delivery, 25(1), 766-772.

Huerta-Angeles, G., Brandejsová, M., Kulhánek, J., Pavlík, V., Šmejkalová, D., Vágnerová, H., \& Velebný, V. (2016). Linolenic acid grafted hyaluronan: Process development, structural characterization, biological assessing, and stability studies. Carbohydrate Polymers, 152, 815-824.

Huh, K. M., Ooya, T., Lee, W. K., Sasaki, S., Kwon, I. C., Jeong, S. Y., \& Yui, N. (2001). Supramolecularstructured hydrogels showing a reversible phase transition by inclusion complexation between poly (ethylene glycol) grafted dextran and $\alpha$-cyclodextrin. Macromolecules, 34(25), 8657-8662.

Hyon, S. H., Nakajima, N., Sugai, H., \& Matsumura, K. (2014). Low cytotoxic tissue adhesive based on oxidized dextran and epsilon-poly-l-lysine. Journal of Biomedical Materials Research Part A, 102(8), 2511-2520.

Ifuku, S. (2014). Chitin and chitosan nanofibers: Preparation and chemical modifications. Molecules, 19(11), 18367-18380.

Jafarzadeh-Holagh, S., Hashemi-Najafabadi, S., Shaki, H., \& Vasheghani-Farahani, E. (2018). Selfassembled and $\mathrm{pH}$-sensitive mixed micelles as an intracellular doxorubicin delivery system. Journal of colloid and interface science, 523, 179-190.

Jedvert, K., \& Heinze, T. (2017). Cellulose modification and shaping - a review. Journal of Polymer Engineering, 37(9), 845.

Jeong, D., Joo, S.-W., Hu, Y., Shinde, V. V., Cho, E., \& Jung, S. (2018). Carboxymethyl cellulose-based superabsorbent hydrogels containing carboxymehtyl $\beta$-cyclodextrin for enhanced mechanical strength and effective drug delivery. European Polymer Journal, 105, 17-25.

Jiménez Blanco, J. L., Ortiz Mellet, C., \& García Fernández, J. M. (2013). Multivalency in heterogeneous glycoenvironments: hetero-glycoclusters, -glycopolymers and -glycoassemblies. Chemical Society Reviews, 42(11), 4518-4531.

Jóhannsdóttir, S., Jansook, P., Stefánsson, E., \& Loftsson, T. (2015). Development of a cyclodextrinbased aqueous cyclosporin A eye drop formulations. International journal of pharmaceutics, 493(1-2), 86-95.

Jorfi, M., \& Foster, E. J. (2015). Recent advances in nanocellulose for biomedical applications. Journal of Applied Polymer Science, 14(132), 41719.

Joshy, K., George, A., Snigdha, S., Joseph, B., Kalarikkal, N., Pothen, L. A., \& Thomas, S. (2018). Novel core-shell dextran hybrid nanosystem for anti-viral drug delivery. Materials Science and Engineering: C, 93, 864-872.

Kadokawa, J.-i. (2011). Precision polysaccharide synthesis catalyzed by enzymes. Chemical Reviews, $111(7), 4308-4345$. 
Kang, H., Liu, R., \& Huang, Y. (2015). Graft modification of cellulose: methods, properties and applications. Polymer, 70, A1-A16.

Kargarzadeh, H., Mariano, M., Gopakumar, D., Ahmad, I., Thomas, S., Dufresne, A., . . Lin, N. (2018). Advances in cellulose nanomaterials. Cellulose, 25(4), 1-39.

Karimi, M. H., Mahdavinia, G. R., \& Massoumi, B. (2018). pH-controlled sunitinib anticancer release from magnetic chitosan nanoparticles crosslinked with $\mathrm{k}$-carrageenan. Materials Science Engineering: $C, 91,705-714$.

Karmakar, P. D., Seesala, V. S., Pal, A., Dhara, S., Chatterjee, S., \& Pal, S. (2018). Synthesis of RAFTMediated Amphiphilic Graft Copolymeric Micelle Using Dextran and Poly (Oleic Acid) toward Oral Delivery of Nifedipine. Journal of Polymer Science Part A: Polymer Chemistry, 56(20), 2354-2363.

Kayaci, F., \& Uyar, T. (2012). Electrospun zein nanofibers incorporating cyclodextrins. Carbohydrate Polymers, 90(1), 558-568.

Khoshnevisan, K., Maleki, H., Samadian, H., Shahsavari, S., Sarrafzadeh, M. H., Larijani, B., . . . Khorramizadeh, M. R. (2018). Cellulose acetate electrospun nanofibers for drug delivery systems: Applications and recent advances. Carbohydrate Polymers, 198, 131-141.

Khunmanee, S., Jeong, Y., \& Park, H. (2017). Crosslinking method of hyaluronic-based hydrogel for biomedical applications. Journal of tissue engineering, 8, 1-16.

Kida, T., Marui, Y., Miyawaki, K., Kato, E., \& Akashi, M. (2009). Unique organogel formation with a channel-type cyclodextrin assembly. Chemical Communications(26), 3889-3891.

Kiessling, L. L., \& Grim, J. C. (2013). Glycopolymer probes of signal transduction. Chemical Society Reviews, 42(10), 4476-4491.

Kim, B. S., Yang, W. Y., Ryu, J. H., Yoo, Y. S., \& Lee, M. (2005). Carbohydrate-coated nanocapsules from amphiphilic rod-coil molecule: binding to bacterial type 1 pili. Chemical Communications(15), 2035-2037.

Kim, H.-S., Song, M., Lee, E.-J., \& Shin, U. S. (2015). Injectable hydrogels derived from phosphorylated alginic acid calcium complexes. Materials Science Engineering: C, 51, 139-147.

Klemm, D., Heublein, B., Fink, H. P., \& Bohn, A. (2005). Cellulose: fascinating biopolymer and sustainable raw material. Angewandte Chemie International Edition, 44(22), 3358-3393.

Kong, W.-Q., Gao, C.-D., Hu, S.-F., Ren, J.-L., Zhao, L.-H., \& Sun, R.-C. (2017). Xylan-modified-based hydrogels with temperature/pH dual sensitivity and controllable drug delivery behavior. Materials, 10(3), 304.

Kong, W., Dai, Q., Gao, C., Ren, J., Liu, C., \& Sun, R. (2018). Hemicellulose-based hydrogels and their potential application. In Polymer Gels (pp. 87-127): Springer.

Köwitsch, A., Zhou, G., \& Groth, T. (2018). Medical application of glycosaminoglycans: a review. Journal of tissue engineering and regenerative medicine, 12(1), e23-e41.

Krishnan, B. P., Raghu, S., Mukherjee, S., \& Sureshan, K. M. (2016). Organogel-assisted topochemical synthesis of multivalent glyco-polymer for high-affinity lectin binding. Chemical Communications, 52(98), 14089-14092.

Kumar, A., Rao, K. M., \& Han, S. S. (2018). Application of xanthan gum as polysaccharide in tissue engineering: A review. Carbohydrate Polymers, 180, 128-144.

Kumar, S., Kaur, P., Bernela, M., Rani, R., \& Thakur, R. (2016). Ketoconazole encapsulated in chitosangellan gum nanocomplexes exhibits prolonged antifungal activity. International journal of biological macromolecules, 93, 988-994.

Kumbar, S., Toti, U., Deng, M., James, R., Laurencin, C., Aravamudhan, A., .. Ramos, D. (2011). Novel mechanically competent polysaccharide scaffolds for bone tissue engineering. Biomedical Materials, 6(6), 065005.

Laffleur, F., \& Messirek, A. (2016). Development of mucoadhesive thio-carboxymethyl cellulose for application in buccal delivery of drugs. Therapeutic delivery, 7(2), 63-71.

Lai, W.-F., \& Shum, H. C. (2015). Hypromellose-graft-chitosan and its polyelectrolyte complex as novel systems for sustained drug delivery. ACS applied materials \& interfaces, 7(19), 10501-10510. 
Latxague, L., Ramin, M. A., Appavoo, A., Berto, P., Maisani, M., Ehret, C., . . Barthelemy, P. (2015). Control of stem-cell behavior by fine tuning the supramolecular assemblies of low-molecularweight gelators. Angewandte Chemie International Edition, 54(15), 4517-4521.

Lee, D. W., Kim, T., Park, I. S., Huang, Z., \& Lee, M. (2012). Multivalent nanofibers of a controlled length: regulation of bacterial cell agglutination. Journal of the American Chemical Society, 134(36), 14722-14725.

Lee, J.-Y., Chung, S.-J., Cho, H.-J., \& Kim, D.-D. (2015a). Bile acid-conjugated chondroitin sulfate A-based nanoparticles for tumor-targeted anticancer drug delivery. European Journal of Pharmaceutics and Biopharmaceutics, 94, 532-541.

Lee, J.-Y., Park, J.-H., Lee, J.-J., Lee, S. Y., Chung, S.-J., Cho, H.-J., \& Kim, D.-D. (2016). Polyethylene glycolconjugated chondroitin sulfate $A$ derivative nanoparticles for tumor-targeted delivery of anticancer drugs. Carbohydrate Polymers, 151, 68-77.

Lee, J.-Y., Termsarasab, U., Lee, M. Y., Kim, D.-H., Lee, S. Y., Kim, J. S., . . . Kim, D.-D. (2017). Chemosensitizing indomethacin-conjugated chitosan oligosaccharide nanoparticles for tumortargeted drug delivery. Acta biomaterialia, 57, 262-273.

Lee, J. Y., Chung, S. J., Cho, H. J., \& Kim, D. D. (2015b). Phenylboronic acid-decorated chondroitin sulfate A-based theranostic nanoparticles for enhanced tumor targeting and penetration. Advanced Functional Materials, 25(24), 3705-3717.

Lee, S.-J., \& Jeong, Y.-I. (2018). Hybrid nanoparticles based on chlorin e6-conjugated hyaluronic acid/poly (I-histidine) copolymer for theranostic application to tumors. Journal of Materials Chemistry B, 6(18), 2851-2859.

Lee, S. S., Fyrner, T., Chen, F., Alvarez, Z., Sleep, E., Chun, D. S., . . Stupp, S. I. (2017). Sulfated glycopeptide nanostructures for multipotent protein activation. Nature Nanotechnology, 12(8), 821-829.

Lee, Y. C., \& Lee, R. T. (1995). Carbohydrate-protein interactions: basis of glycobiology. Accounts of Chemical Research, 28(8), 321-327.

Lembo, D., Swaminathan, S., Donalisio, M., Civra, A., Pastero, L., Aquilano, D., . . Cavalli, R. (2013). Encapsulation of Acyclovir in new carboxylated cyclodextrin-based nanosponges improves the agent's antiviral efficacy. International journal of pharmaceutics, 443(1-2), 262-272.

Lévesque, S. G., Lim, R. M., \& Shoichet, M. S. (2005). Macroporous interconnected dextran scaffolds of controlled porosity for tissue-engineering applications. Biomaterials, 26(35), 7436-7446.

Li, D., Feng, X., Chen, L., Ding, J., \& Chen, X. (2018). One-step synthesis of targeted acid-labile polysaccharide prodrug for efficiently intracellular drug delivery. ACS Biomaterials Science \& Engineering, 4(2), 539-546.

Li, L., Wang, F., Shao, Z., Liu, J., Zhang, Q., \& Jiao, W. (2018). Chitosan and carboxymethyl cellulosemultilayered magnetic fluorescent systems for reversible protein immobilization. Carbohydrate Polymers, 201, 357-366.

Li, M., Li, H., Li, X., Zhu, H., Xu, Z., Liu, L., . . interfaces. (2017). A bioinspired alginate-gum arabic hydrogel with micro-/nanoscale structures for controlled drug release in chronic wound healing. ACS applied materials \& interfaces, 9(27), 22160-22175.

Li, Q., Gan, L., Tao, H., Wang, Q., Ye, L., Zhang, A., \& Feng, Z. (2016). The synthesis and application of heparin-based smart drug carrier. Carbohydrate Polymers, 140, 260-268.

Li, W., Yi, X., Liu, X., Zhang, Z., Fu, Y., \& Gong, T. (2016). Hyaluronic acid ion-pairing nanoparticles for targeted tumor therapy. Journal of Controlled Release, 225, 170-182.

Li, Z.-P., Jiang, M.-C., Chen, B., Gao, P., Yang, S., Liu, Y.-F., . . Y Yu, C.-Y. (2018). Fabrication and characterization of a novel self-assembling micelle based on chitosan cross-linked pectindoxorubicin conjugates macromolecular pro-drug for targeted cancer therapy. RSC Advances, 8(22), 12004-12016.

Li, Z., Cho, S., Kwon, I. C., Janát-Amsbury, M. M., \& Huh, K. M. (2013). Preparation and characterization of glycol chitin as a new thermogelling polymer for biomedical applications. Carbohydrate Polymers, 92(2), 2267-2275.

Li, Z., Wang, Y., Pei, Y., Xiong, W., Xu, W., Li, B., \& Li, J. (2017). Effect of substitution degree on carboxymethylcellulose interaction with lysozyme. Food Hydrocolloids, 62, 222-229. 
Li, Z., Xu, W., Wang, Y., Shah, B. R., Zhang, C., Chen, Y., .. . Li, B. (2015). Quantum dots loaded nanogels for low cytotoxicity, $\mathrm{pH}$-sensitive fluorescence, cell imaging and drug delivery. Carbohydrate Polymers, 121, 477-485.

Liao, J., Zheng, H., Fei, Z., Lu, B., Zheng, H., Li, D., .. Y Yi, Y. (2018). Tumor-targeting and pH-responsive nanoparticles from hyaluronic acid for the enhanced delivery of doxorubicin. International journal of biological macromolecules, 113, 737-747.

Lim, Y.-b., Park, S., Lee, E., Jeong, H., Ryu, J.-H., Lee, M. S., \& Lee, M. (2007). Glycoconjugate nanoribbons from the self-assembly of carbohydrate- peptide block molecules for controllable bacterial cell cluster formation. Biomacromolecules, 8(5), 1404-1408.

Lin, Y.-J., Mi, F.-L., Lin, P.-Y., Miao, Y.-B., Huang, T., Chen, K.-H., . . Sung, H.-W. (2018). Strategies for improving diabetic therapy via alternative administration routes that involve stimuliresponsive insulin-delivering systems. Advanced Drug Delivery Reviews.

Lis, H., \& Sharon, N. J. C. r. (1998). Lectins: carbohydrate-specific proteins that mediate cellular recognition. 98(2), 637-674.

Liu, C., Wang, J., Huang, S., Yu, L., Wang, Y., Chen, H., \& Wang, D. (2018). Self-assembled nanoparticles for cellular delivery of peptide nucleic acid using amphiphilic N, N, N-trimethyl-O-alkyl chitosan derivatives. Journal of Materials Science: Materials in Medicine, 29(8), 114.

Liu, L., Zhou, C., Xia, X., \& Liu, Y. (2016). Self-assembled lecithin/chitosan nanoparticles for oral insulin delivery: preparation and functional evaluation. International journal of nanomedicine, 11, 761.

Liu, M., Du, H., Khan, A. R., Ji, J., Yu, A., \& Zhai, G. (2018). Redox/enzyme sensitive chondroitin sulfatebased self-assembled nanoparticles loading docetaxel for the inhibition of metastasis and growth of melanoma. Carbohydrate Polymers, 184, 82-93.

Liu, M., Du, H., \& Zhai, G. (2016). Self-assembled nanoparticles based on chondroitin sulfatedeoxycholic acid conjugates for docetaxel delivery: Effect of degree of substitution of deoxycholic acid. Colloids and Surfaces B: Biointerfaces, 146, 235-244.

Liu, N., Higashi, K., Ueda, K., \& Moribe, K. (2017). Effect of guest drug character encapsulated in the cavity and intermolecular spaces of $\psi$-cyclodextrins on the dissolution property of ternary $\gamma^{-}$ cyclodextrin complex. International journal of pharmaceutics, 531(2), 543-549.

Liu, W., Quan, P., Li, Q., Tang, P., Chen, J., Jiang, T., \& Cai, W. (2018). Dextran-based biodegradable nanoparticles: an alternative and convenient strategy for treatment of traumatic spinal cord injury. International journal of nanomedicine, 13, 4121.

Liu, Y., Zhang, Y., Wang, Z., Wang, J., Wei, K., Chen, G., \& Jiang, M. (2016). Building Nanowires from Micelles: Hierarchical Self-Assembly of Alternating Amphiphilic Glycopolypeptide Brushes with Pendants of High-Mannose Glycodendron and Oligophenylalanine. Journal of the American Chemical Society, 138(38), 12387-12394.

Liu, Y., Zhou, C., Wang, W., Yang, J., Wang, H., Hong, W., \& Huang, Y. (2016). CD44 receptor targeting and endosomal $\mathrm{pH}$-sensitive dual functional hyaluronic acid micelles for intracellular paclitaxel delivery. Molecular pharmaceutics, 13(12), 4209-4221.

Liu, Z., Jiao, Y., Wang, Y., Zhou, C., \& Zhang, Z. (2008). Polysaccharides-based nanoparticles as drug delivery systems. Advanced Drug Delivery Reviews, 60(15), 1650-1662.

Lopalco, A., Cutrignelli, A., Denora, N., Perrone, M., lacobazzi, R. M., Fanizza, E., . . Franco, M. (2018). Delivery of proapoptotic agents in glioma cell lines by TSPO ligand-dextran nanogels. International journal of molecular sciences, 19(4), 1155.

Lopes, L. C., Fajardo, A. R., Piai, J. F., Rubira, A. F., \& Muniz, E. C. (2013). Incorporation of theophylline in a chitosan/chondroitin sulfate hydrogel matrix: In vitro release studies and mechanical properties according to $\mathrm{pH}$ changes. Journal of Applied Polymer Science, 128(5), 3417-3424.

Lu, H.-T., Lu, T.-W., Chen, C.-H., Lu, K.-Y., \& Mi, F.-L. (2018). Development of nanocomposite scaffolds based on biomineralization of $\mathrm{N}$, O-carboxymethyl chitosan/fucoidan conjugates for bone tissue engineering. International journal of biological macromolecules, 120, 2335-2345.

Luo, Y., Kirker, K. R., \& Prestwich, G. D. (2000). Cross-linked hyaluronic acid hydrogel films: new biomaterials for drug delivery. Journal of Controlled Release, 69(1), 169-184. 
M Ways, T., Lau, W., \& Khutoryanskiy, V. (2018). Chitosan and its derivatives for application in mucoadhesive drug delivery systems. Polymers, 10(3), 267.

Maciel, V. B., Yoshida, C. M., Pereira, S. M., Goycoolea, F. M., \& Franco, T. T. (2017). Electrostatic selfassembled chitosan-pectin nano-and microparticles for insulin delivery. Molecules, 22(10), 1707.

Mahdavinia, G. R., Mosallanezhad, A., Soleymani, M., \& Sabzi, M. (2017). Magnetic-and pH-responsive $\mathrm{k}$-carrageenan/chitosan complexes for controlled release of methotrexate anticancer drug. International journal of biological macromolecules, 97, 209-217.

Mandal, B., Das, D., Rameshbabu, A. P., Dhara, S., \& Pal, S. (2016). A biodegradable, biocompatible transdermal device derived from carboxymethyl cellulose and multi-walled carbon nanotubes for sustained release of diclofenac sodium. RSC Advances, 6(23), 19605-19611.

Mandracchia, D., Rosato, A., Trapani, A., Chlapanidas, T., Montagner, I. M., Perteghella, S., .. Tripodo, G. (2017). Design, synthesis and evaluation of biotin decorated inulin-based polymeric micelles as long-circulating nanocarriers for targeted drug delivery. Nanomedicine: Nanotechnology, Biology and Medicine, 13(3), 1245-1254.

Manzi, G., Zoratto, N., Matano, S., Sabia, R., Villani, C., Coviello, T., . . Di Meo, C. (2017). "Click" hyaluronan based nanohydrogels as multifunctionalizable carriers for hydrophobic drugs. Carbohydrate Polymers, 174, 706-715.

Marradi, M., Chiodo, F., García, I., \& Penadés, S. (2013). Glyconanoparticles as multifunctional and multimodal carbohydrate systems. Chemical Society Reviews, 42(11), 4728-4745.

Martinez, A., Ortiz Mellet, C., \& Garcia Fernandez, J. M. (2013). Cyclodextrin-based multivalent glycodisplays: covalent and supramolecular conjugates to assess carbohydrate-protein interactions. Chemical Society Reviews, 42(11), 4746-4773.

Martini, M., Hegger, P. S., Schädel, N., Minsky, B. B., Kirchhof, M., Scholl, S., . . Laschat, S. (2016). Charged triazole cross-linkers for hyaluronan-based hybrid hydrogels. Materials, 9(10), 810.

Martins, A., Facchi, S., Follmann, H., Pereira, A., Rubira, A., \& Muniz, E. (2014). Antimicrobial activity of chitosan derivatives containing $\mathrm{N}$-quaternized moieties in its backbone: a review. International journal of molecular sciences, 15(11), 20800-20832.

Martins, J. G., Camargo, S. E., Bishop, T. T., Popat, K. C., Kipper, M. J., \& Martins, A. F. (2018). Pectinchitosan membrane scaffold imparts controlled stem cell adhesion and proliferation. Carbohydrate Polymers, 197(1), 47-56.

Marui, Y., Kida, T., \& Akashi, M. (2009). Facile morphological control of cyclodextrin nano-and microstructures and their unique organogelation ability. Chemistry of Materials, 22(2), 282284.

Masina, N., Choonara, Y. E., Kumar, P., du Toit, L. C., Govender, M., Indermun, S., \& Pillay, V. (2017). A review of the chemical modification techniques of starch. Carbohydrate Polymers, 157, 12261236.

Matelová, A., Huerta-Angeles, G., Šmejkalová, D., Brůnová, Z., Dušek, J., Vícha, R., \& Velebný, V. (2016). Synthesis of novel amphiphilic hyaluronan containing-aromatic fatty acids for fabrication of polymeric micelles. Carbohydrate Polymers, 151, 1175-1183.

Mathiselvam, M., Loganathan, D., \& Varghese, B. (2013). Synthesis and characterization of thioureaand urea-linked glycolipids as low-molecular-weight hydrogelators. RSC Advances, 3(34), 14528.

McCune, D., Guo, X., Shi, T., Stealey, S., Antrobus, R., Kaltchev, M., ... Ren, W. (2018). Electrospinning pectin-based nanofibers: a parametric and cross-linker study. Applied Nanoscience, 8(1-2), 3340.

Meenach, S. A., Kim, Y. J., Kauffman, K. J., Kanthamneni, N., Bachelder, E. M., \& Ainslie, K. M. (2012). Synthesis, optimization, and characterization of camptothecin-loaded acetalated dextran porous microparticles for pulmonary delivery. Molecular pharmaceutics, 9(2), 290-298.

Mehvar, R. (2000). Dextrans for targeted and sustained delivery of therapeutic and imaging agents. Journal of Controlled Release, 69(1), 1-25. 
Mei, L., Liu, Y., Zhang, H., Zhang, Z., Gao, H., \& He, Q. (2016). Antitumor and antimetastasis activities of heparin-based micelle served as both carrier and drug. ACS applied materials interfaces, 8(15), 9577-9589.

Meng, X., Yang, D., Keyvan, G., Michniak-Kohn, B., \& Mitra, S. (2012). Synthesis and immobilization of micro-scale drug particles in presence of $\beta$-cyclodextrins. Colloids and Surfaces $B$ : Biointerfaces, 92, 213-222.

Miao, T., Wang, J., Zeng, Y., Liu, G., \& Chen, X. (2018). Polysaccharide-based controlled release systems for therapeutics delivery and tissue engineering: From bench to bedside. Advanced Science, 5(4), 1700513.

Milovanovic, S., Markovic, D., Aksentijevic, K., Stojanovic, D. B., Ivanovic, J., \& Zizovic, I. (2016). Application of cellulose acetate for controlled release of thymol. Carbohydrate Polymers, 147, 344-353.

Mitra, A., Sarkar, V., \& Mukhopadhyay, B. (2017). Simple carbohydrate-derived multifunctional gels. ChemistrySelect, 2(31), 9958-9961.

Mizrahy, S., \& Peer, D. (2012). Polysaccharides as building blocks for nanotherapeutics. Chemical Society Reviews, 41(7), 2623-2640.

Mohtashamian, S., Boddohi, S., \& Hosseinkhani, S. (2018). Preparation and optimization of selfassembled chondroitin sulfate-nisin nanogel based on quality by design concept. International journal of biological macromolecules, 107, 2730-2739.

Mokhtarzadeh, A., Alibakhshi, A., Hejazi, M., Omidi, Y., \& Dolatabadi, J. E. N. (2016). Bacterial-derived biopolymers: Advanced natural nanomaterials for drug delivery and tissue engineering. $\operatorname{Tr} A C$ Trends in Analytical Chemistry, 82, 367-384.

Monier, M., Abdel-Latif, D., \& Ji, H. (2016). Synthesis and application of photo-active carboxymethyl cellulose derivatives. Reactive and Functional Polymers, 102, 137-146.

Moon, R. J., Martini, A., Nairn, J., Simonsen, J., \& Youngblood, J. (2011). Cellulose nanomaterials review: structure, properties and nanocomposites. Chemical Society Reviews, 40(7), 39413994.

Morelli, A., Betti, M., Puppi, D., \& Chiellini, F. (2016). Design, preparation and characterization of ulvan based thermosensitive hydrogels. Carbohydrate Polymers, 136, 1108-1117.

Morelli, A., \& Chiellini, F. (2010). Ulvan as a new type of biomaterial from renewable resources: functionalization and hydrogel preparation. Macromolecular Chemistry Physics, 211(7), 821832.

Morganti, P., Carezzi, F., Del Ciotto, P., Morganti, G., Nunziata, M., Gao, X., . . Yudin, V. (2014). Nanobiotechnology. UK: Central Press.

Musazzi, U. M., Cencetti, C., Franzé, S., Zoratto, N., Di Meo, C., Procacci, P., . . Cilurzo, F. J. M. p. (2018). Gellan nanohydrogels: Novel nanodelivery systems for sutaneous administration of piroxicam. Molecular pharmaceutics, 15(3), 1028-1036.

Nacereddine, A., Bollacke, A., Róka, E., Marminon, C., Bouaziz, Z., Fenyvesi, F., . . Le Borgne, M. (2018). Self-assembled supramolecular nanoparticles improve the cytotoxic efficacy of CK2 inhibitor THN7. Pharmaceuticals, 11(1), 10.

Naessens, M., Cerdobbel, A., Soetaert, W., \& Vandamme, E. J. (2005). Leuconostoc dextransucrase and dextran: production, properties and applications. Journal of Chemical Technology \& Biotechnology, 80(8), 845-860.

Nagahama, K., Mori, Y., Ohya, Y., \& Ouchi, T. (2007). Biodegradable nanogel formation of polylactidegrafted dextran copolymer in dilute aqueous solution and enhancement of its stability by stereocomplexation. Biomacromolecules, 8(7), 2135-2141.

Nair, A. V., Raman, M., \& Doble, M. (2016). Cyclic $\beta-(1 \rightarrow 3)(1 \rightarrow 6)$ glucan/carrageenan hydrogels for wound healing applications. RSC Advances, 6(100), 98545-98553.

Newland, B., Baeger, M., Eigel, D., Newland, H., Werner, C., \& Engineering. (2017). Oxygen-producing gellan gum hydrogels for dual delivery of either oxygen or peroxide with doxorubicin. ACS Biomaterials Science, 3(5), 787-792. 
Ni, Y., Tang, Z., Cao, W., Lin, H., Fan, Y., Guo, L., \& Zhang, X. (2015). Tough and elastic hydrogel of hyaluronic acid and chondroitin sulfate as potential cell scaffold materials. International journal of biological macromolecules, 74, 367-375.

Niu, X., Zhang, Z., \& Zhong, Y. (2017). Hydrogel loaded with self-assembled dextran sulfate-doxorubicin complexes as a delivery system for chemotherapy. Materials Science and Engineering: $C, 77$, 888-894.

Obaidat, R. M., Alnaief, M., \& Mashaqbeh, H. (2018). Investigation of carrageenan aerogel microparticles as a potential drug carrier. Aaps Pharmscitech, 19(5), 2226-2236.

Ohya, Y., Takahashi, A., \& Kuzuya, A. (2018). Preparation of biodegradable oligo (lactide) s-grafted dextran nanogels for efficient drug delivery by controlling intracellular traffic. International journal of molecular sciences, 19(6), 1606.

Olteanu, A. A., Aramă, C.-C., Radu, C., Mihăescu, C., \& Monciu, C.-M. (2014). Effect of $\beta$-cyclodextrins based nanosponges on the solubility of lipophilic pharmacological active substances (repaglinide). Journal of inclusion phenomena and macrocyclic chemistry, 80(1-2), 17-24.

Osmałek, T., Froelich, A., \& Tasarek, S. (2014). Application of gellan gum in pharmacy and medicine. International journal of pharmaceutics, 466(1-2), 328-340.

Ou, X., Zheng, J., Zhao, X., \& Liu, M. (2018). Chemically cross-linked chitin nanocrystal scaffolds for drug delivery. ACS Applied Nano Materials, 1(12), 6790-6799.

Panza, M., Pistorio, S. G., Stine, K. J., \& Demchenko, A. V. (2018). Automated chemical oligosaccharide synthesis: Novel approach to traditional challenges. Chemical Reviews, 118, 8105-8150.

Paolicelli, P., Petralito, S., Varani, G., Nardoni, M., Pacelli, S., Di Muzio, L., . . Casadei, M. A. (2018). Effect of glycerol on the physical and mechanical properties of thin gellan gum films for oral drug delivery. International journal of pharmaceutics, 547(1-2), 226-234.

Pardeshi, C. V., \& Belgamwar, V. S. (2018). N, N, Ntrimethyl chitosan modified flaxseed oil based mucoadhesive neuronanoemulsions for direct nose to brain drug delivery. International journal of biological macromolecules, 120, 2560-2571.

Pardo-Vargas, A., Delbianco, M., \& Seeberger, P. H. (2018). Automated glycan assembly as an enabling technology. Current Opinion in Chemical Biology, 46, 48-55.

Park, H., Woo, E. K., \& Lee, K. Y. (2014). Ionically cross-linkable hyaluronate-based hydrogels for injectable cell delivery. Journal of Controlled Release, 196, 146-153.

Park, W., Park, S.-j., \& Na, K. (2010). Potential of self-organizing nanogel with acetylated chondroitin sulfate as an anti-cancer drug carrier. Colloids Surfaces B: Biointerfaces, 79(2), 501-508.

Patel, S., \& Goyal, A. (2015). Applications of natural polymer gum arabic: a review. International Journal of Food Properties, 18(5), 986-998.

Pathak, N. P., Halder, T., Dhara, S., \& Yadav, S. (2017). Partially Acetylated or Benzoylated Arabinose Derivatives as Structurally Simple Organogelators: Effect of the Ester Protecting Group on Gel Properties. Chemistry-A European Journal, 23(47), 11323-11329.

Payne, W. M., Svechkarev, D., Kyrychenko, A., \& Mohs, A. M. (2018). The role of hydrophobic modification on hyaluronic acid dynamics and self-assembly. Carbohydrate Polymers, 182, 132-141.

Pedrosa, S. S., Pereira, P., Correia, A., Moreira, S., Rocha, H., \& Gama, F. M. (2016). Biocompatibility of a Self-Assembled Crosslinkable Hyaluronic Acid Nanogel. Macromolecular Bioscience, 16(11), 1610-1620.

Percec, V., Leowanawat, P., Sun, H. J., Kulikov, O., Nusbaum, C. D., Tran, T. M., . . Heiney, P. A. (2013). Modular synthesis of amphiphilic Janus glycodendrimers and their self-assembly into glycodendrimersomes and other complex architectures with bioactivity to biomedically relevant lectins. Journal of the American Chemical Society, 135(24), 9055-9077.

Perrone, M., Lopalco, A., Lopedota, A., Cutrignelli, A., Laquintana, V., Douglas, J., . . Tongiani, S. (2017). Preactivated thiolated glycogen as mucoadhesive polymer for drug delivery. European Journal of Pharmaceutics and Biopharmaceutics, 119, 161-169.

Perrone, M., Lopedota, A., Liberati, E., Russo, V., Cutrignelli, A., Laquintana, V., . . Denora, N. (2017). Natural dendrimers: Synthesis and in vitro characterization of glycogen-cysteamine conjugates. European Journal of Pharmaceutics and Biopharmaceutics, 115, 168-176. 
Petzold-Welcke, K., Schwikal, K., Daus, S., \& Heinze, T. (2014). Xylan derivatives and their application potential-Mini-review of own results. Carbohydrate Polymers, 100, 80-88.

Phaechamud, T., \& Mahadlek, J. (2015). Solvent exchange-induced in situ forming gel comprising ethyl cellulose-antimicrobial drugs. International journal of pharmaceutics, 494(1), 381-392.

Picheth, G. F., Pirich, C. L., Sierakowski, M. R., Woehl, M. A., Sakakibara, C. N., de Souza, C. F., . . de Freitas, R. A. (2017). Bacterial cellulose in biomedical applications: A review. International journal of biological macromolecules, 104, 97-106.

Piras, A. M., Zambito, Y., Burgalassi, S., Monti, D., Tampucci, S., Terreni, E., . . Chetoni, P. (2018). A water-soluble, mucoadhesive quaternary ammonium chitosan-methyl- $\beta$-cyclodextrin conjugate forming inclusion complexes with dexamethasone. Journal of Materials Science: Materials in Medicine, 29(4), 42.

Pires, R. A., Abul-Haija, Y. M., Costa, D. S., Novoa-Carballal, R., Reis, R. L., Ulijn, R. V., \& Pashkuleva, I. (2015). Controlling cancer cell fate using localized biocatalytic self-assembly of an aromatic carbohydrate amphiphile. Journal of the American Chemical Society, 137(2), 576-579.

Pramod, P., Shah, R., Chaphekar, S., Balasubramanian, N., \& Jayakannan, M. (2014). Polysaccharide nano-vesicular multidrug carriers for synergistic killing of cancer cells. Nanoscale, 6(20), 1184111855.

Prezotti, F. G., Boni, F. I., Ferreira, N. N., Campana-Filho, S. P., Almeida, A., Vasconcelos, T., . . . Sarmento, B. (2018). Gellan Gum/Pectin Beads Are Safe and Efficient for the Targeted Colonic Delivery of Resveratrol. Polymers, 10(1), 50.

Priya, M. V., Sabitha, M., \& Jayakumar, R. (2016). Colloidal chitin nanogels: A plethora of applications under one shell. Carbohydrate Polymers, 136, 609-617.

Quiñones, J. P., Peniche, H., \& Peniche, C. (2018). Chitosan based self-assembled nanoparticles in drug delivery. Polymers, 10(3), 235.

Raemdonck, K., Demeester, J., \& De Smedt, S. (2009). Advanced nanogel engineering for drug delivery. Soft Matter, 5(4), 707-715.

Rahimian, K., Wen, Y., \& Oh, J. K. (2015). Redox-responsive cellulose-based thermoresponsive grafted copolymers and in-situ disulfide crosslinked nanogels. Polymer, 72, 387-394.

Rajendiran, N., Sankaranarayanan, R., \& Saravanan, J. (2014). A study of supramolecular host-guest interaction of dothiepin and doxepin drugs with cyclodextrin macrocycles. Journal of Molecular Structure, 1067, 252-260.

Rajewski, R. A., \& Stella, V. J. (1996). Pharmaceutical applications of cyclodextrins. 2. In vivo drug delivery. Journal of pharmaceutical sciences, 85(11), 1142-1169.

Ramburrun, P., Kumar, P., Choonara, Y. E., du Toit, L. C., \& Pillay, V. (2017). Design and characterization of neurodurable gellan-xanthan $\mathrm{pH}$-responsive hydrogels for controlled drug delivery. Expert opinion on drug delivery, 14(3), 291-306.

Rasoulzadeh, M., \& Namazi, H. (2017). Carboxymethyl cellulose/graphene oxide bio-nanocomposite hydrogel beads as anticancer drug carrier agent. Carbohydrate Polymers, 168, 320-326.

Real, D., Leonardi, D., Williams, R. O., Repka, M. A., \& Salomon, C. J. (2018). Solving the delivery problems of triclabendazole using cyclodextrins. Aaps Pharmscitech, 19(5), 2311-2321.

Rinaudo, M. (2006). Chitin and chitosan: properties and applications. Progress in polymer science, 31(7), 603-632.

Rnjak-Kovacina, J., Tang, F., Whitelock, J. M., \& Lord, M. S. (2018). Glycosaminoglycan and Proteoglycan-Based Biomaterials: Current Trends and Future Perspectives. Advanced healthcare materials, 7(6), 1701042.

Rochín-Wong, S., Rosas-Durazo, A., Zavala-Rivera, P., Maldonado, A., Martínez-Barbosa, M., Vélaz, I., \& Tánori, J. (2018). Drug Release Properties of Diflunisal from Layer-By-Layer Self-Assembled K-Carrageenan/Chitosan Nanocapsules: Effect of Deposited Layers. Polymers, 10(7), 760.

Rodriguez-Torres, M. d. P., Acosta-Torres, L. S., \& Diaz-Torres, L. A. (2018). Heparin-based nanoparticles: An overview of their applications. Journal of Nanomaterials, 2018.

Rojo, J., Morales, J. C., \& Penadés, S. (2002). Carbohydrate-Carbohydrate Interactions in Biological and Model Systems. In S. Penadés (Ed.), Host-Guest Chemistry: Mimetic Approaches to Study Carbohydrate Recognition (pp. 45-92). Berlin, Heidelberg: Springer Berlin Heidelberg. 
Rosselgong, J., Chemin, M., Almada, C. C., Hemery, G., Guigner, J.-M., Chollet, G., . . Grau, E. (2018). Synthesis and self-assembly of Xylan-based amphiphiles: from bio-based vesicles to antifungal properties. Biomacromolecules, 20, 118-129.

Roy, D., Semsarilar, M., Guthrie, J. T., \& Perrier, S. (2009). Cellulose modification by polymer grafting: a review. Chemical Society Reviews, 38(7), 2046-2064.

Roy, R., \& Kim, J. M. (2003). Cu(II)-Self-assembling bipyridyl-glycoclusters and dendrimers bearing the Tn-antigen cancer marker: syntheses and lectin binding properties. Tetrahedron, 59(22), 38813893.

Rusa, C. C., Bullions, T. A., Fox, J., Porbeni, F. E., Wang, X., \& Tonelli, A. E. (2002). Inclusion compound formation with a new columnar cyclodextrin host. Langmuir, 18(25), 10016-10023.

Ruthes, A. C., Smiderle, F. R., \& lacomini, M. (2015). d-Glucans from edible mushrooms: A review on the extraction, purification and chemical characterization approaches. Carbohydrate Polymers, 117, 753-761.

Ryu, J.-H., Lee, E., Lim, Y.-b., \& Lee, M. (2007). Carbohydrate-coated supramolecular structures: Transformation of nanofibers into spherical micelles triggered by guest encapsulation. Journal of the American Chemical Society, 129(15), 4808-4814.

Sahariah, P., \& Másson, M. r. (2017). Antimicrobial chitosan and chitosan derivatives: a review of the structure-activity relationship. Biomacromolecules, 18(11), 3846-3868.

Salamanca, C. H., Yarce, C. J., Moreno, R. A., Prieto, V., \& Recalde, J. (2018). Natural gum-type biopolymers as potential modified nonpolar drug release systems. Carbohydrate Polymers, 189, 31-38.

Salim, M., Abou-Zied, O. K., Kulathunga, H. U., Baskaran, A., Kuppusamy, U. R., \& Hashim, R. (2015). Alkyl mono- and di-glucoside sugar vesicles as potential drug delivery vehicles: detecting drug release using fluorescence. RSC Advances, 5(68), 55536-55543.

Samadian, H., Mobasheri, H., Hasanpour, S., \& Majid, R. F. (2017). Needleless electrospinning system, an efficient platform to fabricate carbon nanofibers. Paper presented at the Journal of Nano Research.

Sami, A. J., Khalid, M., Jamil, T., Aftab, S., Mangat, S. A., Shakoori, A., \& Iqbal, S. (2018). Formulation of novel chitosan guargum based hydrogels for sustained drug release of paracetamol. International journal of biological macromolecules, 108, 324-332.

Sansone, F., \& Casnati, A. (2013). Multivalent glycocalixarenes for recognition of biological macromolecules: glycocalyx mimics capable of multitasking. Chemical Society Reviews, 42(11), 4623-4639.

Sathuvan, M., Thangam, R., Gajendiran, M., Vivek, R., Balasubramanian, S., Nagaraj, S., . . Rengasamy, R. (2017). k-Carrageenan: an effective drug carrier to deliver curcumin in cancer cells and to induce apoptosis. Carbohydrate Polymers, 160, 184-193.

Sato, S., Yoshimasa, Y., Fujita, D., Yagi-Utsumi, M., Yamaguchi, T., Kato, K., \& Fujita, M. (2015). A selfassembled spherical complex displaying a gangliosidic glycan cluster capable of interacting with amyloidogenic proteins. Angewandte Chemie International Edition, 54(29), 8435-8439.

Schmidt, B. V., \& Barner-Kowollik, C. (2017). Dynamic macromolecular material design-The Versatility of Cyclodextrin-Based Host-Guest Chemistry. Angewandte Chemie International Edition, 56(29), 8350-8369.

Schulze, P., Gericke, M., Scholz, F., Wondraczek, H., Miethe, P., \& Heinze, T. (2016). Incorporation of hydrophobic dyes within cellulose acetate and acetate phthalate based nanoparticles. Macromolecular Chemistry and Physics, 217(16), 1823-1833.

Seabra, A. B., Bernardes, J. S., Fávaro, W. J., Paula, A. J., \& Durán, N. (2017). Cellulose nanocrystals as carriers in medicine and their toxicities: A review. Carbohydrate Polymers, 181, 514-527.

Sehgal, R. R., Roohani-Esfahani, S., Zreiqat, H., \& Banerjee, R. (2017). Nanostructured gellan and xanthan hydrogel depot integrated within a baghdadite scaffold augments bone regeneration. Journal of tissue engineering regenerative medicine, 11(4), 1195-1211.

Selvamuthukumar, S., Anandam, S., Krishnamoorthy, K., \& Rajappan, M. (2012). Nanosponges: A novel class of drug delivery system-review. Journal of Pharmacy \& Pharmaceutical Sciences, 15(1), 103-111. 
Shaki, H., Ganji, F., Kempen, P. J., Dolatshahi-Pirouz, A., \& Vasheghani-Farahani, E. (2018). Selfassembled amphiphilic-dextran nanomicelles for delivery of rapamycin. Journal of Drug Delivery Science and Technology, 44, 333-341.

Shalumon, K., Binulal, N., Selvamurugan, N., Nair, S., Menon, D., Furuike, T., . . Jayakumar, R. (2009). Electrospinning of carboxymethyl chitin/poly (vinyl alcohol) nanofibrous scaffolds for tissue engineering applications. Carbohydrate Polymers, 77(4), 863-869.

Sharaf, S., \& El-Naggar, M. E. (2018). Eco-friendly technology for preparation, characterization and promotion of honey bee propolis extract loaded cellulose acetate nanofibers in medical domains. Cellulose, 25(9), 5195-5204.

Shariatinia, Z. (2018). Carboxymethyl chitosan: Properties and biomedical applications. International journal of biological macromolecules, 120, 1406-1419.

Shekarforoush, E., Ajalloueian, F., Zeng, G., Mendes, A. C., \& Chronakis, I. S. (2018). Electrospun xanthan gum-chitosan nanofibers as delivery carrier of hydrophobic bioactives. Materials Letters, 228, 322-326.

Shigemitsu, H., \& Kida, T. (2018). Preparation of nano-and microstructures through molecular assembly of cyclic oligosaccharides. Polymer Journal(50), 541-550.

Shivhare, K., Garg, C., Priyam, A., Gupta, A., Sharma, A. K., \& Kumar, P. (2018). Enzyme sensitive smart inulin-dehydropeptide conjugate self-assembles into nanostructures useful for targeted delivery of ornidazole. International journal of biological macromolecules, 106, 775-783.

Shu, X. Z., Liu, Y., Palumbo, F. S., Luo, Y., \& Prestwich, G. D. (2004). In situ crosslinkable hyaluronan hydrogels for tissue engineering. Biomaterials, 25(7-8), 1339-1348.

Shukla, S., \& Shukla, A. (2018). Tunable antibiotic delivery from gellan hydrogels. Journal of Materials Chemistry B, 6(40), 6444-6458.

Silva, S. S., Mano, J. F., \& Reis, R. L. (2017). Ionic liquids in the processing and chemical modification of chitin and chitosan for biomedical applications. Green Chemistry, 19(5), 1208-1220.

Singh, R. S., Kaur, N., \& Kennedy, J. F. (2015). Pullulan and pullulan derivatives as promising biomolecules for drug and gene targeting. Carbohydrate Polymers, 123, 190-207.

Singh, R. S., Kaur, N., Rana, V., \& Kennedy, J. F. (2016). Recent insights on applications of pullulan in tissue engineering. Carbohydrate Polymers, 153, 455-462.

Šmejkalová, D., Muthný, T., Nešporová, K., Hermannová, M., Achbergerová, E., Huerta-Angeles, G., . . . Luptáková, D. (2017). Hyaluronan polymeric micelles for topical drug delivery. Carbohydrate Polymers, 156, 86-96.

Sonawane, R. O., \& Patil, S. D. (2018). Fabrication and statistical optimization of starch-k-carrageenan cross-linked hydrogel composite for extended release pellets of zaltoprofen. International journal of biological macromolecules, 120, 2324-2334.

Song, J., Wang, H., Yang, Y., Xiao, Z., Lin, H., Jin, L., . . Zhu, M. (2018). Nanogels of carboxymethyl chitosan and lysozyme encapsulated amorphous calcium phosphate to occlude dentinal tubules. Journal of Materials Science: Materials in Medicine, 29(6), 84.

Sood, S., Gupta, V. K., Agarwal, S., Dev, K., \& Pathania, D. (2017). Controlled release of antibiotic amoxicillin drug using carboxymethyl cellulose-cl-poly (lactic acid-co-itaconic acid) hydrogel. International journal of biological macromolecules, 101, 612-620.

Soumya, S., Sajesh, K., Jayakumar, R., Nair, S., \& Chennazhi, K. (2012). Development of a phytochemical scaffold for bone tissue engineering using Cissus quadrangularis extract. Carbohydrate Polymers, 87(2), 1787-1795.

Stella, V. J., \& Rajewski, R. A. (1997). Cyclodextrins: their future in drug formulation and delivery. Pharmaceutical research, 14(5), 556-567.

Sun, G., \& Chu, C.-C. (2009). Self-assembly of chemically engineered hydrophilic dextran into microscopic tubules. ACS nano, 3(5), 1176-1182.

Sun, G., \& Chu, C.-C. (2011). Biodegradable nanospheres self-assembled from complementary hydrophilic dextran macromers. Carbohydrate Polymers, 86(2), 910-916.

Sun, G., \& Mao, J. J. (2012). Engineering dextran-based scaffolds for drug delivery and tissue repair. Nanomedicine, 7(11), 1771-1784. 
Sun, G., Shen, Y.-I., Kusuma, S., Fox-Talbot, K., Steenbergen, C. J., \& Gerecht, S. (2011). Functional neovascularization of biodegradable dextran hydrogels with multiple angiogenic growth factors. Biomaterials, 32(1), 95-106.

Sun, J., \& Zhou, Z. (2018). A novel ocular delivery of brinzolamide based on gellan gum: in vitro and in vivo evaluation. Drug Design, Development and Therapy, 12, 383-389.

Sun, L., Ma, X., Dong, C. M., Zhu, B., \& Zhu, X. (2012). NIR-responsive and lectin-binding doxorubicinloaded nanomedicine from Janus-type dendritic PAMAM amphiphiles. Biomacromolecules, 13(11), 3581-3591.

Sun, W., Saldaña, M. D., Fan, L., Zhao, Y., Dong, T., Jin, Y., \& Zhang, J. (2016). Sulfated polysaccharide heparin used as carrier to load hydrophobic lappaconitine. International journal of biological macromolecules, 84, 275-280.

Sung, H.-W., Sonaje, K., Liao, Z.-X., Hsu, L.-W., \& Chuang, E.-Y. (2012). pH-responsive nanoparticles shelled with chitosan for oral delivery of insulin: from mechanism to therapeutic applications. Accounts of Chemical Research, 45(4), 619-629.

Swierczewska, M., Han, H. S., Kim, K., Park, J. H., \& Lee, S. (2016). Polysaccharide-based nanoparticles for theranostic nanomedicine. Advanced Drug Delivery Reviews, 99, 70-84.

Szente, L., Szejtli, J., \& Kis, G. L. (1998). Spontaneous opalescence of aqueous $\psi$-Cyclodextrin solutions: Complex formation or self-aggregation? Journal of pharmaceutical sciences, 87(6), 778-781.

Tada, D., Tanabe, T., Tachibana, A., \& Yamauchi, K. (2007). Albumin-crosslinked alginate hydrogels as sustained drug release carrier. Materials Science Engineering: C, 27(4), 870-874.

Tan, J., Wang, X., Yu, Z., Luo, J., Lan, B., Li, N., .. Z Zhang, L.-M. (2018). Spectroscopic investigation of a hyperbranched cationic amylopectin derivative as a multi-guest molecular host for targeted delivery of a photosensitizer to pancreatic cancer cells. Carbohydrate Polymers, 197, 38-46.

Thomas, B., Raj, M. C., Joy, J., Moores, A., Drisko, G. L., \& Sanchez, C. m. (2018). Nanocellulose, a versatile green platform: From biosources to materials and their applications. Chemical Reviews, 118, 11575-11625.

Tian, Q., Wang, X.-H., Wang, W., Zhang, C.-N., Wang, P., \& Yuan, Z. (2012). Self-assembly and liver targeting of sulfated chitosan nanoparticles functionalized with glycyrrhetinic acid. Nanomedicine: Nanotechnology, Biology Medicine, 8(6), 870-879.

Tønnesen, H. H., \& Karlsen, J. (2002). Alginate in drug delivery systems. Drug development and industrial pharmacy, 28(6), 621-630.

Toomari, Y., Namazi, H., \& Akbar, E. A. (2015). Synthesis of the dendritic type $\beta$-cyclodextrin on primary face via click reaction applicable as drug nanocarrier. Carbohydrate Polymers, 132, 205-213.

Toskas, G., Heinemann, S., Heinemann, C., Cherif, C., Hund, R.-D., Roussis, V., \& Hanke, T. (2012). Ulvan and ulvan/chitosan polyelectrolyte nanofibrous membranes as a potential substrate material for the cultivation of osteoblasts. Carbohydrate Polymers, 89(3), 997-1002.

Trotta, F., Caldera, F., Dianzani, C., Argenziano, M., Barrera, G., \& Cavalli, R. (2016). Glutathione bioresponsive cyclodextrin nanosponges. ChemPlusChem, 81(5), 439-443.

Tsiapla, A.-R., Karagkiozaki, V., Bakola, V., Pappa, F., Gkertsiou, P., Pavlidou, E., \& Logothetidis, S. (2018). Biomimetic and biodegradable cellulose acetate scaffolds loaded with dexamethasone for bone implants. Beilstein journal of nanotechnology, 9(1), 1986-1994.

Tziveleka, L.-A., Pippa, N., Georgantea, P., loannou, E., Demetzos, C., \& Roussis, V. (2018). Marine sulfated polysaccharides as versatile polyelectrolytes for the development of drug delivery nanoplatforms: Complexation of ulvan with lysozyme. International journal of biological macromolecules, 118, 69-75.

Upadhyaya, L., Singh, J., Agarwal, V., Pandey, A., Verma, S. P., Das, P., \& Tewari, R. (2014). In situ grafted nanostructured $\mathrm{ZnO} /$ carboxymethyl cellulose nanocomposites for efficient delivery of curcumin to cancer. Journal of Polymer Research, 21(9), 550.

Upadhyaya, L., Singh, J., Agarwal, V., \& Tewari, R. P. (2014). The implications of recent advances in carboxymethyl chitosan based targeted drug delivery and tissue engineering applications. Journal of Controlled Release, 186, 54-87. 
Ustun Yaylaci, S., Sardan Ekiz, M., Arslan, E., Can, N., Kilic, E., Ozkan, H., . . Guler, M. O. (2016). Supramolecular GAG-like self-assembled glycopeptide nanofibers induce chondrogenesis and cartilage regeneration. Biomacromolecules, 17(2), 679-689.

Uyar, T., Balan, A., Toppare, L., \& Besenbacher, F. (2009). Electrospinning of cyclodextrin functionalized poly (methyl methacrylate)(PMMA) nanofibers. Polymer, 50(2), 475-480.

Uyar, T., \& Besenbacher, F. (2009). Electrospinning of cyclodextrin functionalized polyethylene oxide (PEO) nanofibers. European Polymer Journal, 45(4), 1032-1037.

Uyar, T., Hunt, M. A., Gracz, H. S., \& Tonelli, A. E. (2006). Crystalline cyclodextrin inclusion compounds formed with aromatic guests: Guest-dependent stoichiometries and hydration-sensitive crystal structures. Crystal growth \& design, 6(5), 1113-1119.

Uyar, T., Nur, Y., Hacaloglu, J., \& Besenbacher, F. (2009). Electrospinning of functional poly (methyl methacrylate) nanofibers containing cyclodextrin-menthol inclusion complexes. Nanotechnology, 20(12), 125703.

Vafaei, S. Y., Esmaeili, M., Amini, M., Atyabi, F., Ostad, S. N., \& Dinarvand, R. (2016). Self assembled hyaluronic acid nanoparticles as a potential carrier for targeting the inflamed intestinal mucosa. Carbohydrate Polymers, 144, 371-381.

Van Tomme, S. R., \& Hennink, W. E. (2007). Biodegradable dextran hydrogels for protein delivery applications. Expert Review of Medical Devices, 4(2), 147-164.

Varan, G., Benito, J. M., Mellet, C. O., \& Bilensoy, E. (2017). Development of polycationic amphiphilic cyclodextrin nanoparticles for anticancer drug delivery. Beilstein journal of nanotechnology, 8 , 1457-1468.

Varan, G., Varan, C., Erdoğar, N., Hıncal, A. A., \& Bilensoy, E. (2017). Amphiphilic cyclodextrin nanoparticles. International journal of pharmaceutics, 531(2), 457-469.

Varghese, O. P., Liu, J., Sundaram, K., Hilborn, J., \& Oommen, O. P. (2016). Chondroitin sulfate derived theranostic nanoparticles for targeted drug delivery. Biomaterials science, 4(9), 1310-1313.

Varshosaz, J., Ahmadi, F., Emami, J., Tavakoli, N., Minaiyan, M., Mahzouni, P., \& Dorkoosh, F. (2011). Microencapsulation of budesonide with dextran by spray drying technique for colon-targeted delivery: an in vitro/in vivo evaluation in induced colitis in rat. Journal of microencapsulation, 28(1), 62-73.

Wahid, F., Zhou, Y.-N., Wang, H.-S., Wan, T., Zhong, C., \& Chu, L.-Q. (2018). Injectable self-healing carboxymethyl chitosan-zinc supramolecular hydrogels and their antibacterial activity. International journal of biological macromolecules, 114, 1233-1239.

Wang, B., Chen, K., Yang, R., Yang, F., \& Liu, J. (2014). Stimulus-responsive polymeric micelles for the light-triggered release of drugs. Carbohydrate Polymers, 103, 510-519.

Wang, J., Zhao, W., Chen, H., Qin, A., \& Zhu, P. (2017). Anti-tumor Study of Chondroitin SulfateMethotrexate Nanogels. Nanoscale Research Letters, 12(1), 572.

Wang, T., Hou, J., Su, C., Zhao, L., \& Shi, Y. (2017). Hyaluronic acid-coated chitosan nanoparticles induce ROS-mediated tumor cell apoptosis and enhance antitumor efficiency by targeted drug delivery via CD44. Journal of Nanobiotechnology, 15(1), 7.

Wang, T., Nie, J., \& Yang, D. (2012). Dextran and gelatin based photocrosslinkable tissue adhesive. Carbohydrate Polymers, 90(4), 1428-1436.

Wang, X., Guo, Y., Li, D., Chen, H., \& Sun, R.-c. (2012). Fluorescent amphiphilic cellulose nanoaggregates for sensing trace explosives in aqueous solution. Chemical Communications, 48(45), 55695571.

Wang, X., Wang, J., Li, J., Huang, H., Sun, X., \& Lv, Y. (2018). Development and evaluation of hyaluronic acid-based polymeric micelles for targeted delivery of photosensitizer for photodynamic therapy in vitro. Journal of Drug Delivery Science and Technology, 48, 414-421.

Wasiak, I., Kulikowska, A., Janczewska, M., Michalak, M., Cymerman, I. A., Nagalski, A., . . Ciach, T. (2016). Dextran nanoparticle synthesis and properties. PLoS One, 11(1), e0146237.

Wei, X., Xiong, H., He, S., Wang, Y., Zhou, D., Jing, X., \& Huang, Y. (2017). A facile way to prepare functionalized dextran nanogels for conjugation of hemoglobin. Colloids and Surfaces $B$ : Biointerfaces, 155, 440-448. 
Wen, L., Edmunds, G., Gibbons, C., Zhang, J., Gadi, M. R., Zhu, H., . . Wang, P. G. (2018). Toward Automated Enzymatic Synthesis of Oligosaccharides. Chemical Reviews, 118(17), 8151-8187.

Wenz, G. (1994). Cyclodextrins as building blocks for supramolecular structures and functional units. Angewandte Chemie International Edition in English, 33(8), 803-822.

Wondraczek, H., Kotiaho, A., Fardim, P., \& Heinze, T. (2011). Photoactive polysaccharides. Carbohydrate Polymers, 83(3), 1048-1061.

$\mathrm{Wu}, \mathrm{A}$. , Shen, X., \& He, Y. (2006a). Investigation on $\mathrm{Y}$-cyclodextrin nanotube induced by $\mathrm{N}, \mathrm{N}^{\prime}$ diphenylbenzidine molecule. Journal of colloid and interface science, 297(2), 525-533.

Wu, A., Shen, X., \& He, Y. (2006b). Micrometer-sized rodlike structure formed by the secondary assembly of cyclodextrin nanotube. Journal of colloid and interface science, 302(1), 87-94.

Wu, M., Ni, C., Yao, B., Zhu, C., Huang, B., \& Zhang, L. (2013). Covalently cross-linked and hydrophobically modified alginic acid hydrogels and their application as drug carriers. Polymer Engineering Science, 53(8), 1583-1589.

Xiong, T., Li, X., Zhou, Y., Song, Q., Zhang, R., Lei, L., \& Li, X. (2018). Glycosylation-enhanced biocompatibility of the supramolecular hydrogel of an anti-inflammatory drug for topical suppression of inflammation. Acta biomaterialia, 73, 275-284.

Xu, B., Jiang, G., Yu, W., Liu, D., Liu, Y., Kong, X., \& Yao, J. (2017). Preparation of poly (lactic-co-glycolic acid) and chitosan composite nanocarriers via electrostatic self assembly for oral delivery of insulin. Materials Science Engineering: $C, 78,420-428$.

Xu, T., Xu, X., Gu, Y., Fang, L., \& Cao, F. (2018). Functional intercalated nanocomposites with chitosanglutathione-glycylsarcosine and layered double hydroxides for topical ocular drug delivery. International journal of nanomedicine, 13, 917.

Yadav, R., \& Kikkeri, R. (2012). Carbohydrate functionalized iron(III) complexes as biomimetic siderophores. Chemical Communications, 48(11), 1704-1706.

Yan, G., Yamaguchi, T., Suzuki, T., Yanaka, S., Sato, S., Fujita, M., \& Kato, K. (2017). Hyper-assembly of self-assembled glycoclusters mediated by specific carbohydrate-carbohydrate interactions. Chemistry-An Asian Journal, 12(9), 968-972.

Yang, X., Cai, X., Yu, A., Xi, Y., \& Zhai, G. (2017). Redox-sensitive self-assembled nanoparticles based on alpha-tocopherol succinate-modified heparin for intracellular delivery of paclitaxel. Journal of Colloid Interface Science, 496, 311-326.

Ye, Z., Zhang, Q., Wang, S., Bharate, P., Varela-Aramburu, S., Lu, M., .. Yin, J. (2016). Tumour-targeted drug delivery with mannose-functionalized nanoparticles self-assembled from amphiphilic $\beta$ cyclodextrins. Chemistry-A European Journal, 22(43), 15216-15221.

Yegappan, R., Selvaprithiviraj, V., Amirthalingam, S., \& Jayakumar, R. (2018). Carrageenan based hydrogels for drug delivery, tissue engineering and wound healing. Carbohydrate Polymers, 198, 385-400.

Yeh, M.-k., Cheng, K.-m., Hu, C.-s., Huang, Y.-c., \& Young, J.-j. (2011). Novel protein-loaded chondroitin sulfate-chitosan nanoparticles: Preparation and characterization. Acta biomaterialia, $7(10)$, 3804-3812.

Yin, T., Wang, Y., Chu, X., Fu, Y., Wang, L., Zhou, J., . . . Huo, M. (2018). Free adriamycin-loaded $\mathrm{pH} /$ reduction dual-responsive hyaluronic acid-adriamycin prodrug micelles for efficient cancer therapy. ACS applied materials interfaces, 10(42), 35693-35704.

Yoo, W., Yoo, D., Hong, E., Jung, E., Go, Y., Singh, S. B., . . . Lee, D. (2018). Acid-activatable oxidative stress-inducing polysaccharide nanoparticles for anticancer therapy. Journal of Controlled Release, 269, 235-244.

Yu, C., Gao, C., Lü, S., Chen, C., Huang, Y., \& Liu, M. (2013). Redox-responsive shell-sheddable micelles self-assembled from amphiphilic chondroitin sulfate-cholesterol conjugates for triggered intracellular drug release. Chemical Engineering Journal, 228, 290-299.

Yu, C., Gao, C., Lü, S., Chen, C., Yang, J., Di, X., \& Liu, M. (2014). Facile preparation of pH-sensitive micelles self-assembled from amphiphilic chondroitin sulfate-histamine conjugate for triggered intracellular drug release. Colloids Surfaces B: Biointerfaces, 115, 331-339. 
Yu, Y., Chen, J., Chen, R., Cao, L., Tang, W., Lin, D., . . Liu, C. (2015). Enhancement of VEGF-mediated angiogenesis by 2-N, 6-O-sulfated chitosan-coated hierarchical PLGA scaffolds. ACS applied materials interfaces, $7(18)$, 9982-9990.

Zhang, H., Shen, J., Liu, Z., Hao, A., Bai, Y., \& An, W. (2010). Multi-responsive cyclodextrin vesicles assembled by 'supramolecular bola-amphiphiles'. Supramolecular Chemistry, 22(5), 297-310.

Zhang, H., Xu, J., Xing, L., Ji, J., Yu, A., \& Zhai, G. (2017). Self-assembled micelles based on Chondroitin sulfate/poly (D, L-lactideco-glycolide) block copolymers for doxorubicin delivery. Journal of Colloid Interface Science, 492, 101-111.

Zhang, L., Cheng, H., Zheng, C., Dong, F., Man, S., Dai, Y., \& Yu, P. (2016). Structural and release properties of amylose inclusion complexes with ibuprofen. Journal of Drug Delivery Science and Technology, 31, 101-107.

Zhang, R., Tang, M., Bowyer, A., Eisenthal, R., \& Hubble, J. (2005). A novel pH-and ionic-strengthsensitive carboxy methyl dextran hydrogel. Biomaterials, 26(22), 4677-4683.

Zhang, R., Tao, Y., Xu, W., Xiao, S., Du, S., Zhou, Y., \& Hasan, A. (2018). Rheological and controlled release properties of hydrogels based on mushroom hyperbranched polysaccharide and xanthan gum. International journal of biological macromolecules, 120, 2399-2409.

Zhang, S., Moussodia, R. O., Murzeau, C., Sun, H. J., Klein, M. L., Vertesy, S., . . Percec, V. (2015). Dissecting molecular aspects of cell interactions using glycodendrimersomes with programmable glycan presentation and engineered human lectins. Angewandte Chemie International Edition, 54(13), 4036-4040.

Zhang, S., Moussodia, R. O., Sun, H. J., Leowanawat, P., Muncan, A., Nusbaum, C. D., . . Percec, V. (2014). Mimicking biological membranes with programmable glycan ligands self-assembled from amphiphilic Janus glycodendrimers. Angewandte Chemie International Edition, 53(41), 10899-10903.

Zhao, F., Heesters, B. A., Chiu, I., Gao, Y., Shi, J., Zhou, N., . . Xu, B. (2014). L-Rhamnose-containing supramolecular nanofibrils as potential immunosuppressive materials. Organic \& Biomolecular Chemistry, 12(35), 6816-6819.

Zhong, C., Cooper, A., Kapetanovic, A., Fang, Z., Zhang, M., \& Rolandi, M. (2010). A facile bottom-up route to self-assembled biogenic chitin nanofibers. Soft Matter, 6(21), 5298-5301.

Zhu, J.-Y., Lei, Q., Yang, B., Jia, H.-Z., Qiu, W.-X., Wang, X., . . Zhang, X.-Z. (2015). Efficient nuclear drug translocation and improved drug efficacy mediated by acidity-responsive boronate-linked dextran/cholesterol nanoassembly. Biomaterials, 52, 281-290.

Zhu, K., Ye, T., Liu, J., Peng, Z., Xu, S., Lei, J., . . . Li, B. (2013). Nanogels fabricated by lysozyme and sodium carboxymethyl cellulose for 5 -fluorouracil controlled release. International journal of pharmaceutics, 441(1-2), 721-727.

Zhu, Y., Wang, X., Chen, J., Zhang, J., Meng, F., Deng, C., . . Zhong, Z. (2016). Bioresponsive and fluorescent hyaluronic acid-iodixanol nanogels for targeted X-ray computed tomography imaging and chemotherapy of breast tumors. Journal of Controlled Release, 244, 229-239. 